Journal of Sustainable Agricultural Sciences
http://jsas.journals.ekb.eg/
معحافظة زلبراع الصوب الزراعية بالتوصيات الفنية للمكافحة المتكاملة لآفات محاصيل الخضر

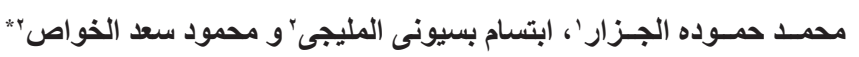

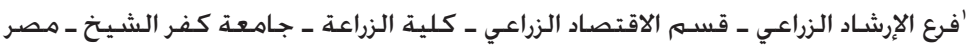

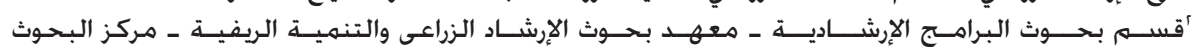

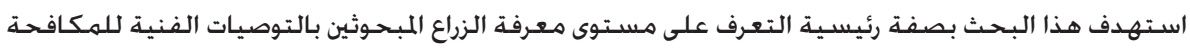

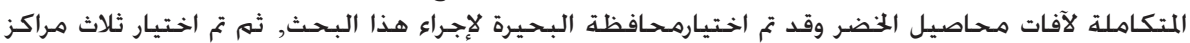

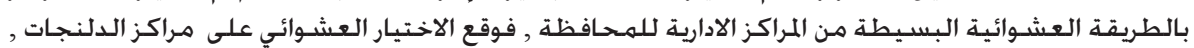

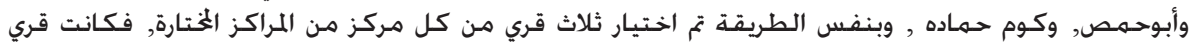

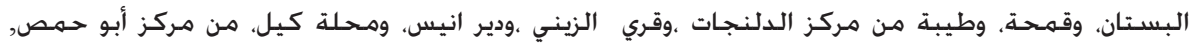

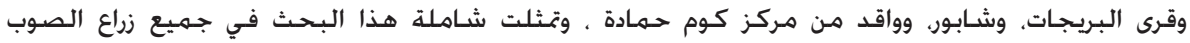

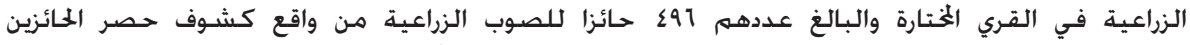

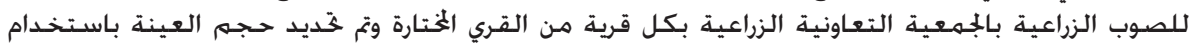

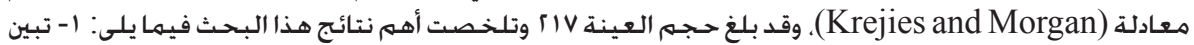

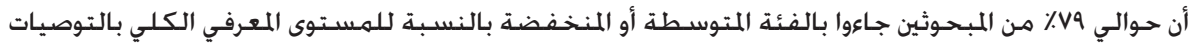

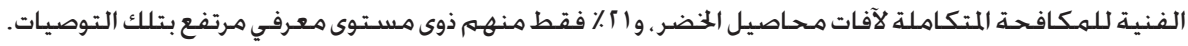

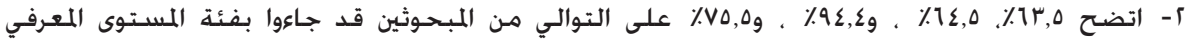

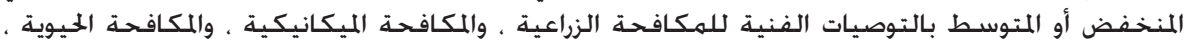

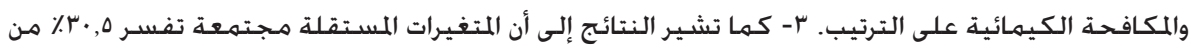
التباين في المتغير التابع.

الركيزة الأسـاسية لدور وزارة الزراعة, وعصب جناح السياسـة

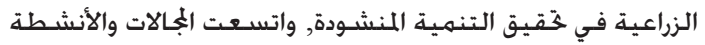

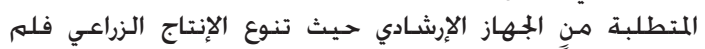

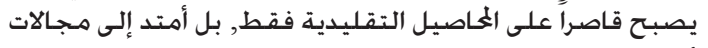

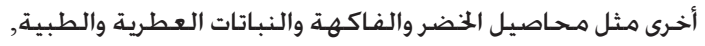
وغير ذلك من الأنشطة المتعلقة بالبيئة, والتسـويقر والمرأة الريفية،

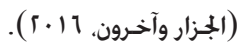

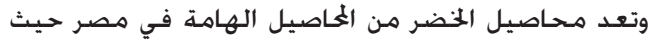

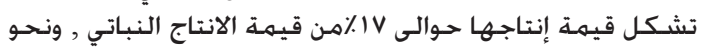

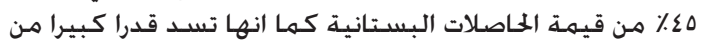

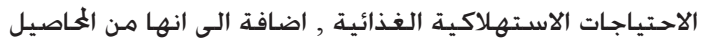

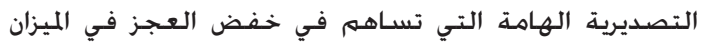

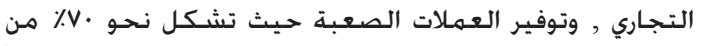

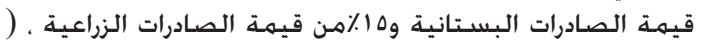

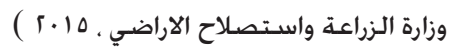

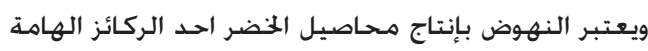

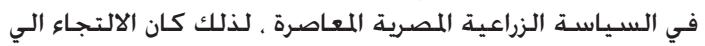

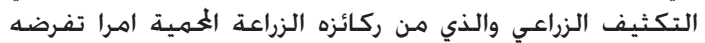
اعتبارات محدودية الموارد الارضية الزراعية بالإضافة الي الزية الزيادة الزية الزية الزية
المقدمة ومشكلة البحث

أصبح حتديث قطاع الزراعة وختقيق التنمية المتواصلة من أهمٍ

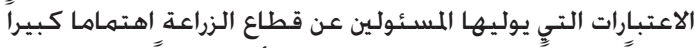

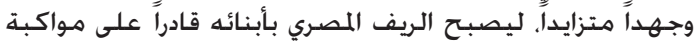

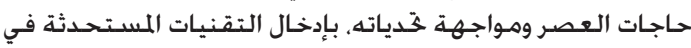

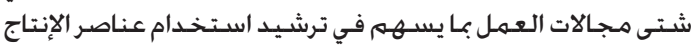

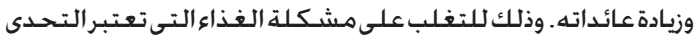

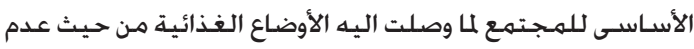

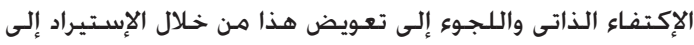

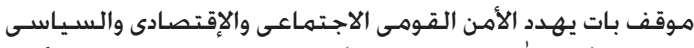

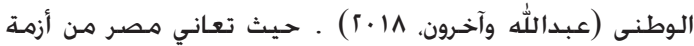

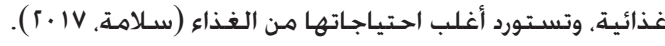

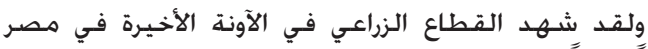

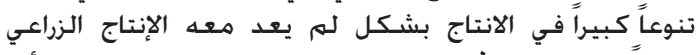

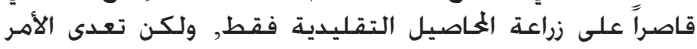

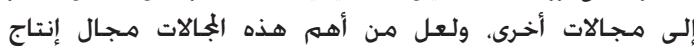

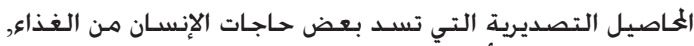

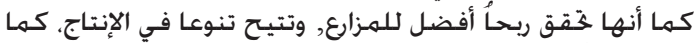

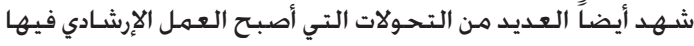

"Corresponding Author: elkhowasss2020@yahoo.com DOI : $10.21608 /$ jsas.2020.26361.1210

Received:22/3/2020; Accepted:20/4/2020

C2020 National Information and Documentation Center (NIDOC) 
ولتلافي الآثار الضارة للمبيدات والعافظة على البيئة، كانت

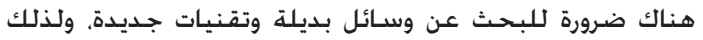

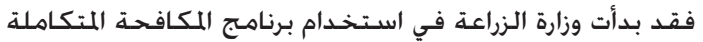

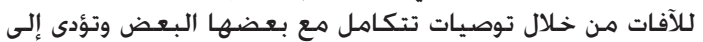

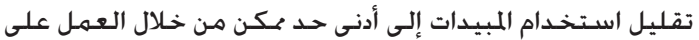

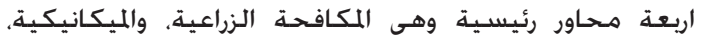

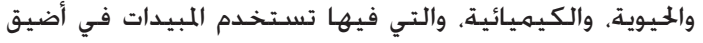

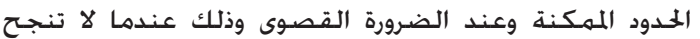

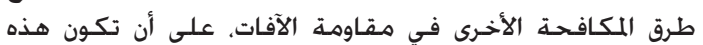

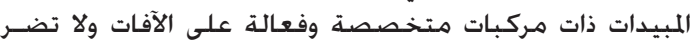

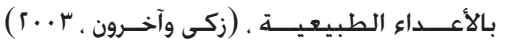

ولتحقيق النجاح في مكافحـة الآفات مع تلافى الآثار

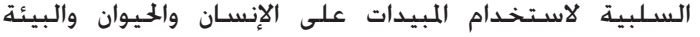

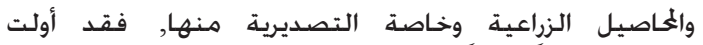

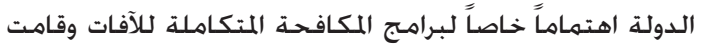

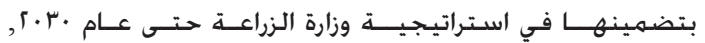

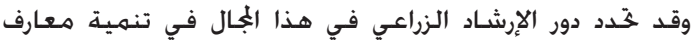

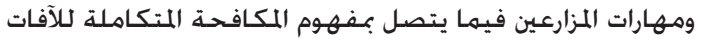

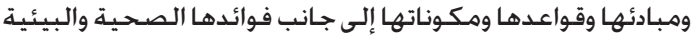

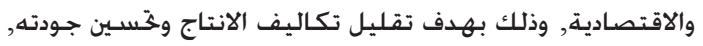

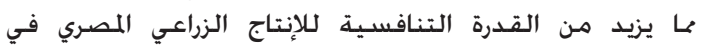

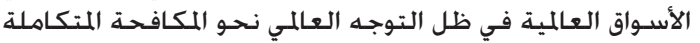

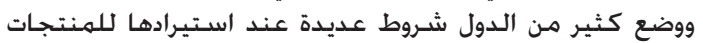

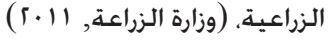

ويرجع سـوء استخـدام المبيدات بصفة عامة وفى محاصيل

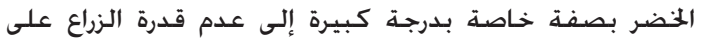

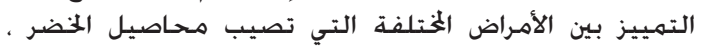

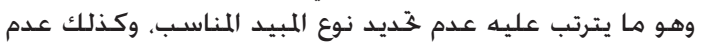

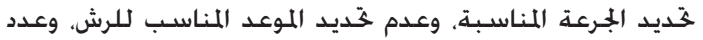

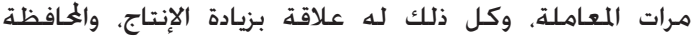

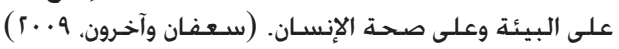

ومما سبق يتضح ضرورة زيادة الإنتاجية من محاصيل

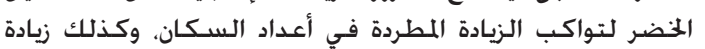

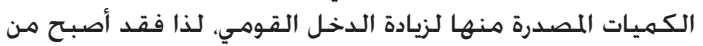

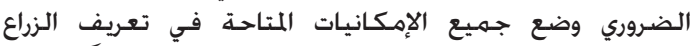

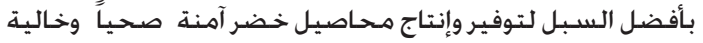

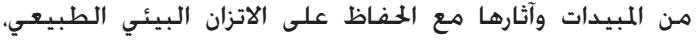

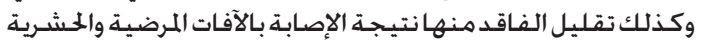

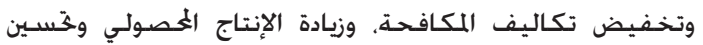

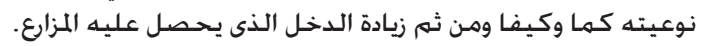

ومن هذا المنطلق فإن مشكلة هذا البحث تتمحسور حول الإجـابة

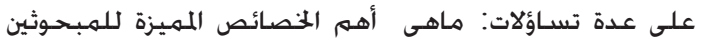

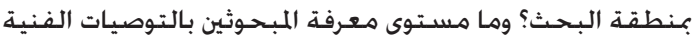

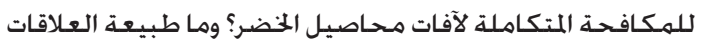

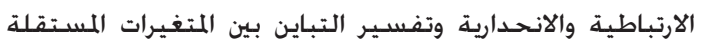

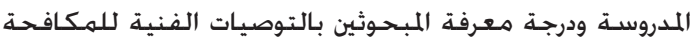

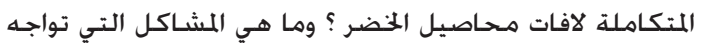

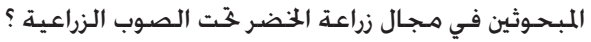

أهداف البحث

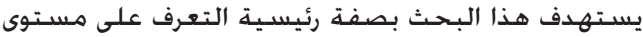

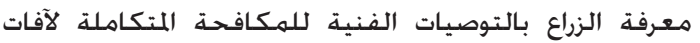

المضطردة في الطلب المحلي علي الغذاء لتلبية للنمو السـريع

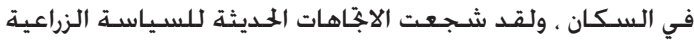

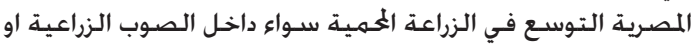

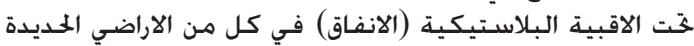

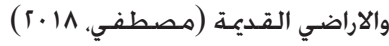

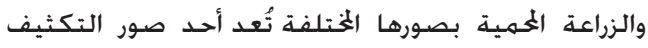

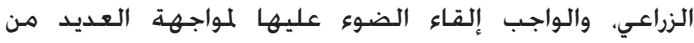

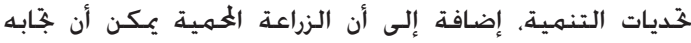

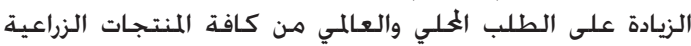

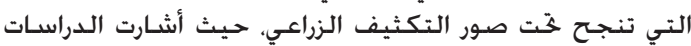

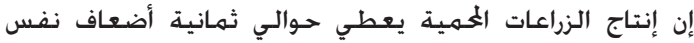

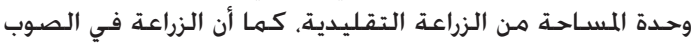

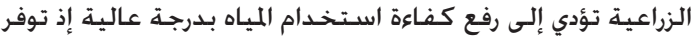

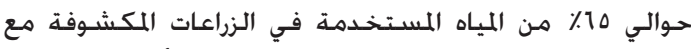

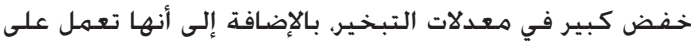

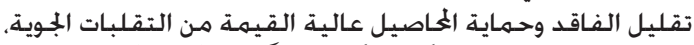

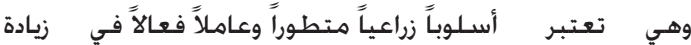

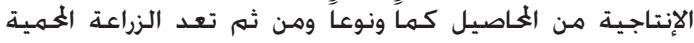

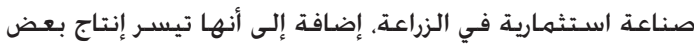
الحاصلات ذات العائد النقدي المرتفع في غير المير الموعد التقليدي.

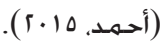

وتصاب محاصيل الخضر بالكثير من الأمراض والحشرات

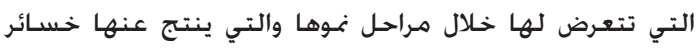

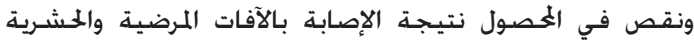

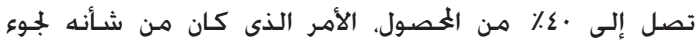

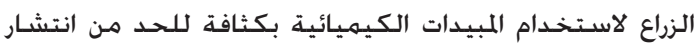

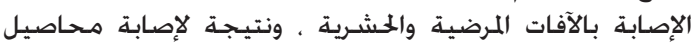

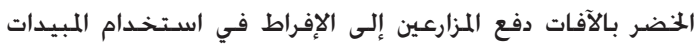

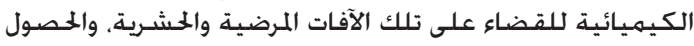

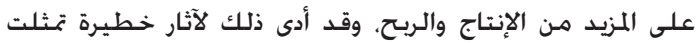

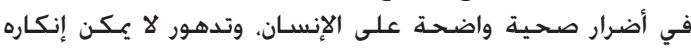

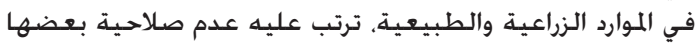

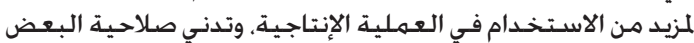

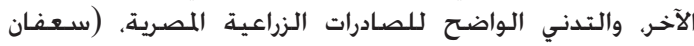

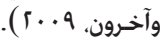

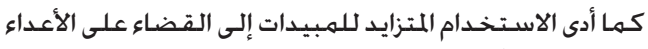

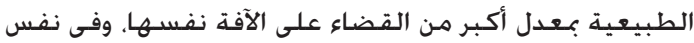

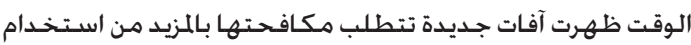

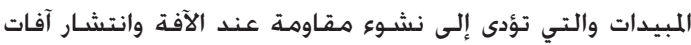

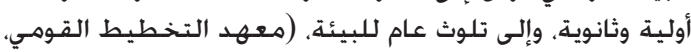

.(1994

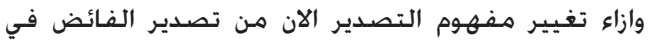

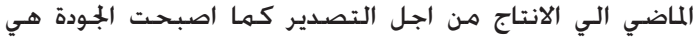

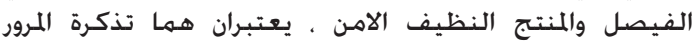

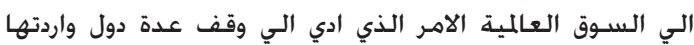

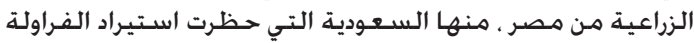

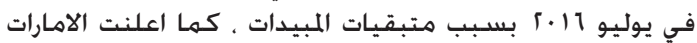

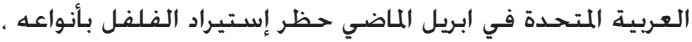

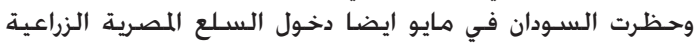

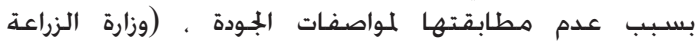

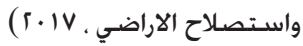

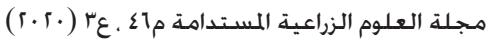




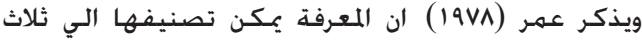

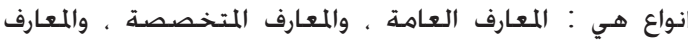
المهنية.

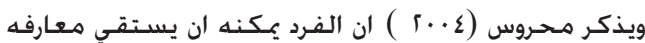

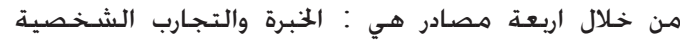

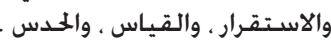

يؤكد عبد المقصود (1911) أن المعرفة هى أولى مراحل

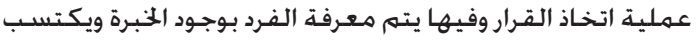

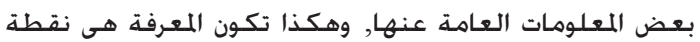

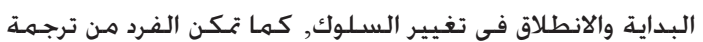

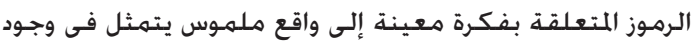

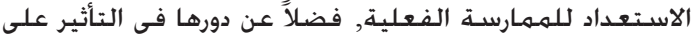
ميول واجتاهات وقيم و معتقدات واهتمامات الأفراد.

ويرى قشطة (1991) أن التغييرات السـلوكية تمثل الهدف

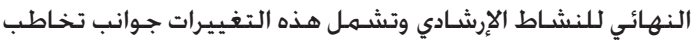

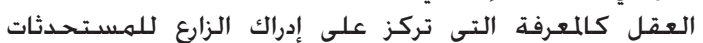

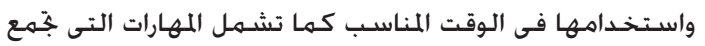

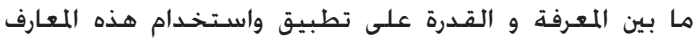

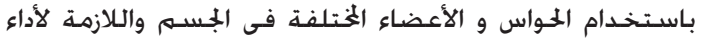

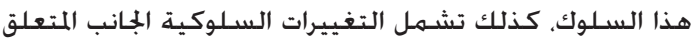

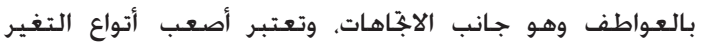

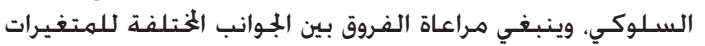

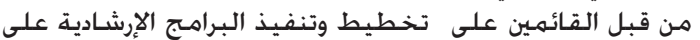

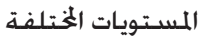

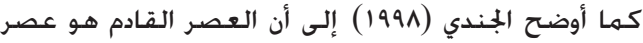

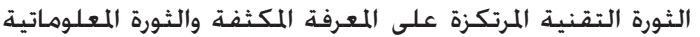

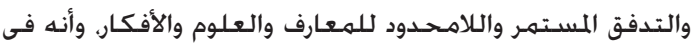

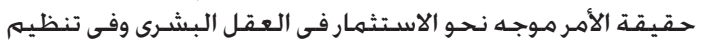

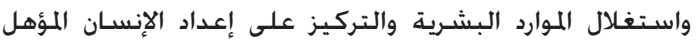

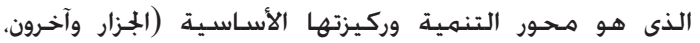

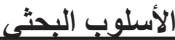

أولاً: التعاريف الإجرائية: التصنية

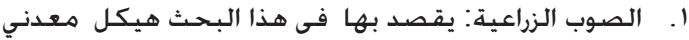

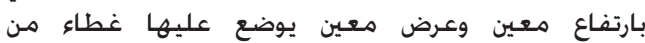

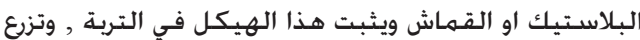

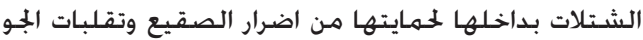

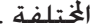

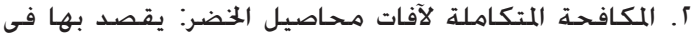

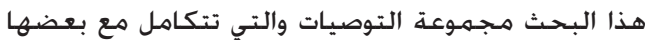

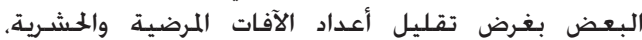

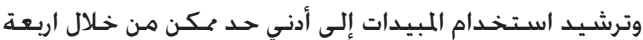

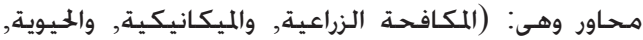

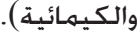

rا. معرفة الزراع المبحـوثين بالتوصيات الفنية للمكافحـة المتكاملة

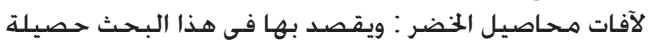

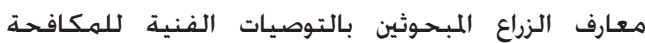

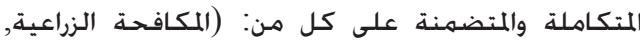
والميكانيكية, والحيوية, والكيمائية).

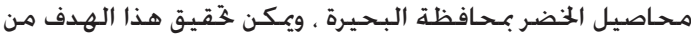
خلال خَقيق الأهداف الفرعية التالية:

ا- - التعرف على بعض الخصائص المميزة للزراع المبحوثين ميطقة البحث.

أ- التعرف على مستـوى معرفة الزراع المبحوثين بالتوصيات الفنية للمكافحة المتكاملة لآفات محاصيل الخراع لميحري

r- التعرف على العلاقات الارتباطية وتفسير التباين بين درجة

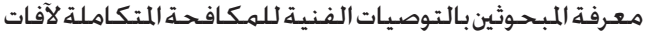
محاصيل الخضر وبين المتغيرات المستقلة المدروسـة.

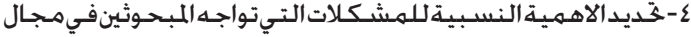
زراعة الخضر حتّ الصوب الزراعية من وجهة نظرهـم .

الاستعراض المرجعي

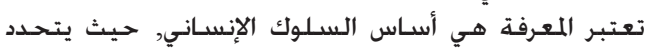

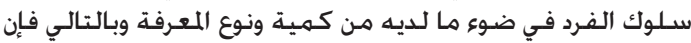

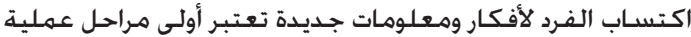

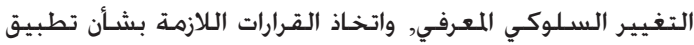

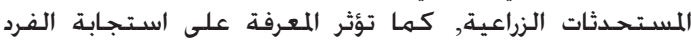

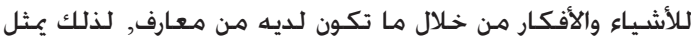

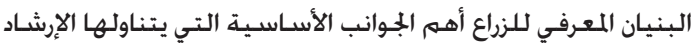

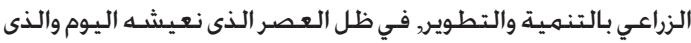

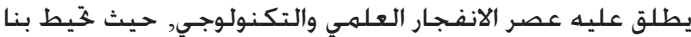

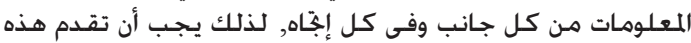

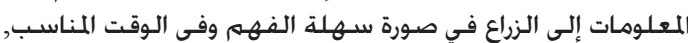

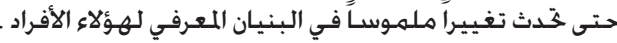

وقد عرفها حنفي (·1994) على أنها هي تلك المعلومات والحقائق والأسس والمبادئ وكل ما يريد أن يعرفه الإنسـان.

أما الرافعي (1999) فيرى أن المعرفة هى القدر من إدراك

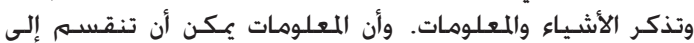

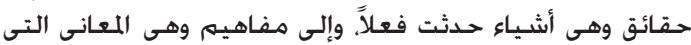

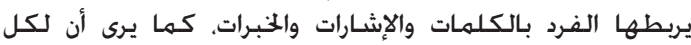

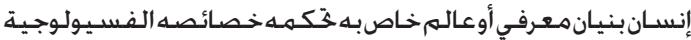

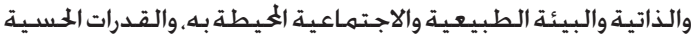

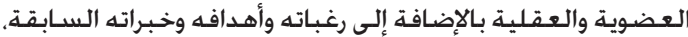
ما يجعل هذا البنيان المعرفي يكاد يكون فريداً لكل فرد.

بينما يذكر سـام (1998) أن المعرفة هى البناء المنظم

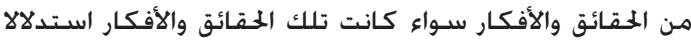

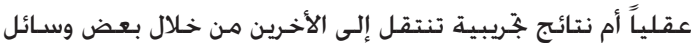

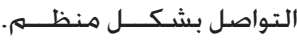

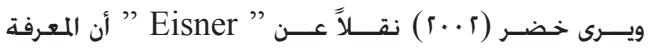

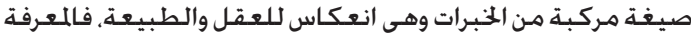
يتم تشكيلها و ابتكارها و لا يته اكتشـافهـا.

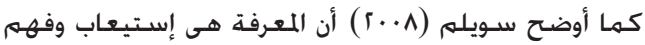

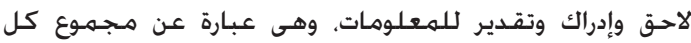

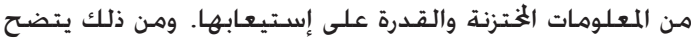

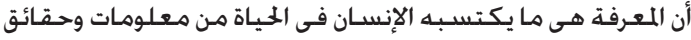

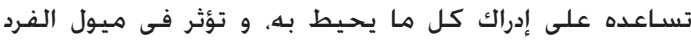
وإجتاهاته واهتماماته ومعتقداته وعواطفه.

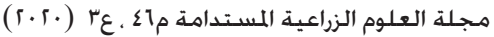


معنوياً في تفسـير التباين في درجـة معرفة المبحـوثين بالتوصيات

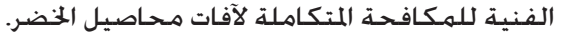

$$
\begin{aligned}
& \text { وسـيتهم اختبار هذه الفـروض في صـورتها الصفرية . } \\
& \text { رابعاً : منطقة وشـاملة وعينة البحـث: }
\end{aligned}
$$

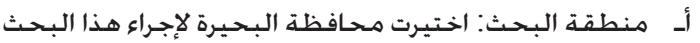

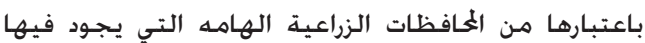

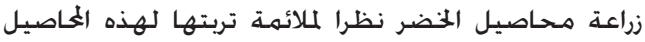

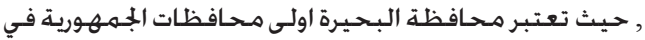
انتاج محاصيل الخضر , وثاني الغحافظات في في الزراعات الخدات

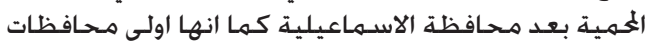

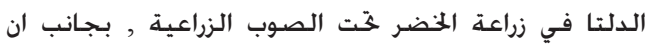

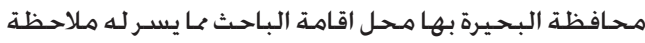

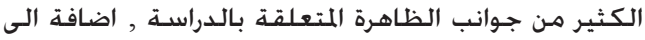

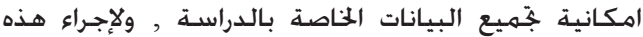

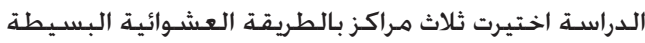
من المراكز الادارية للمححافظة , فوقع الاختيار العشـوائي

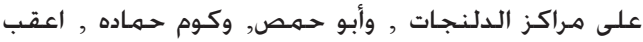

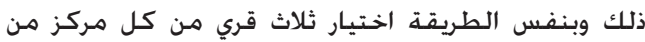

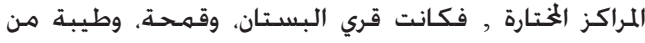

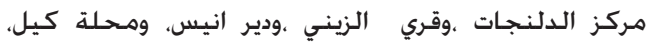

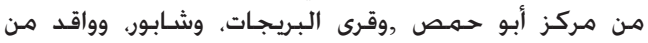

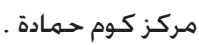

ب- شـاملة وعينة البحـث: تمثلت شـاملة هذا البحـث فـ جـميع زراع

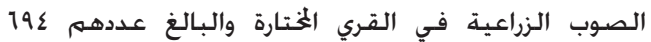
حائزا للصوب الزراعية من واقع كشـوف حصر الحسائزين

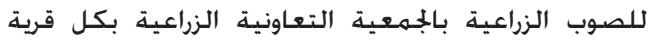

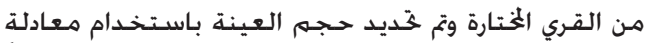

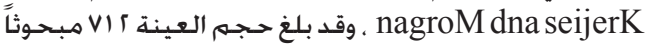

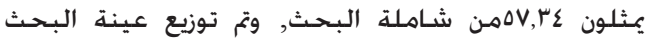
بنفس توزيع الجُتمع الاصلي كما هو مـوضلح باملجدول:

$$
\text { خامسـاً: جهمع وخدّليل البيانات }
$$

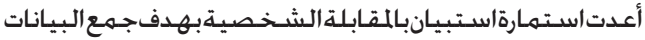

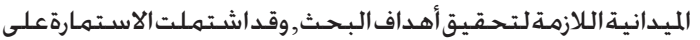

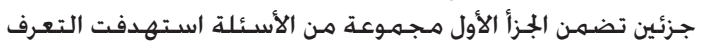

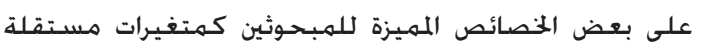

ثانياً : المتغيرات البحثيـة:

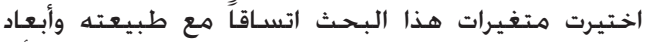

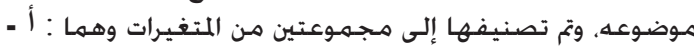

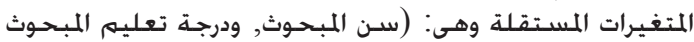

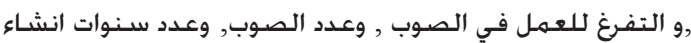

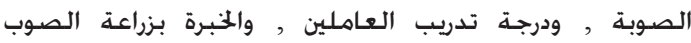

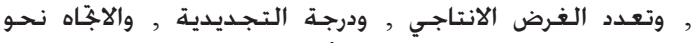

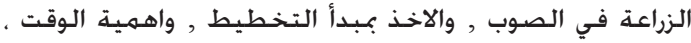

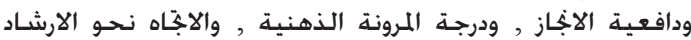

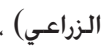

ب ـ المتغير التابع: تمثل المتغير التابع لهذا البحث في درجـة

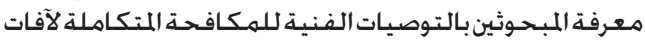

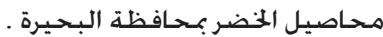

ثالثا :الفـروض البحثية:

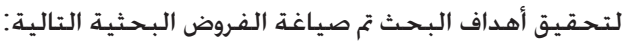

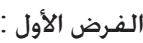

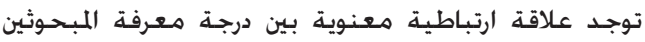

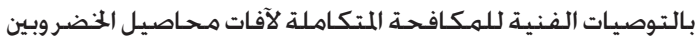

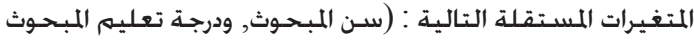

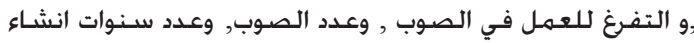

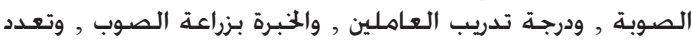

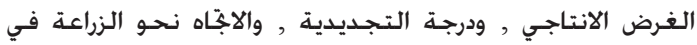

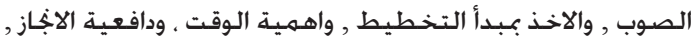

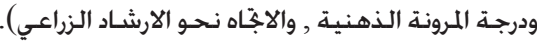

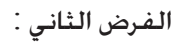

ترتبط المتغيرات المستقلة والمتـمثلة في (سـن المبحـوثر,

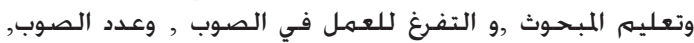

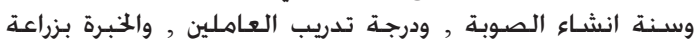
الصوب , وتعدد الغرض الانتاجي , ودرجـة التجديدية , والاجنّاه

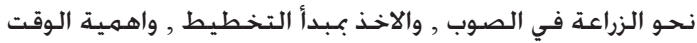

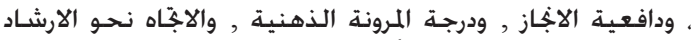

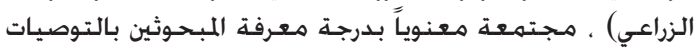

\begin{tabular}{|c|c|c|c|c|}
\hline العينة & الشاملة & القري & م & المركز \\
\hline$r T$ & 7. & البستان & 1 & \multirow{4}{*}{ الدلنجات } \\
\hline 11 & $\varepsilon r$ & قمحة & r & \\
\hline ro & 07 & طيبة & $r$ & \\
\hline iv & r人 & الزيني & 1 & \\
\hline$r T$ & 71 & دير انيس & r & \multirow{2}{*}{ أبو حمص } \\
\hline$r$. & $\leqslant 0$ & محلة كيل & $r$ & \\
\hline וT & vi & البريجات & 1 & \multirow{4}{*}{ كوم حمادة } \\
\hline YI & $\varepsilon V$ & شابور & r & \\
\hline rr & $V T$ & واقد & $r$ & \\
\hline rIV & $\leq 97$ & & & \\
\hline
\end{tabular}

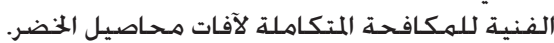

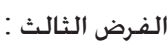

يسـهم كل متغير من المتغيرات المسـتقلة المدروســة إسـهاماً

جدول 1ـ شاملة وعينة البحث لزراع الصوب بالمر اكز الثلاث بمحافظة البحيرة موسم 9 ـ ـ م

المصدر: محافظة البحيرة، مديرية الزراعة, سـجلات قسـم الإحصاء، بيانات رسـمية غير منشـورة, 19 •ام

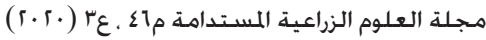


9- درجـة التجديدية: تم قياس هذا المتغير من خلال سؤال المبحوث

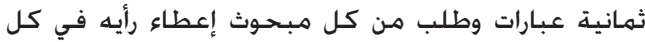

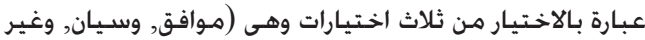

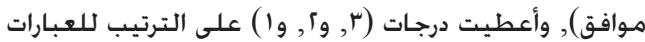

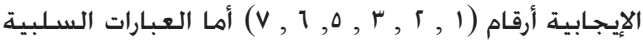

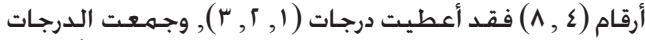

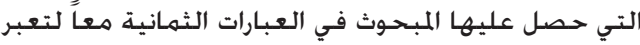
عن هذا المتغير.

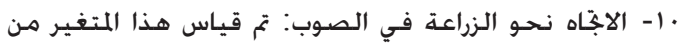

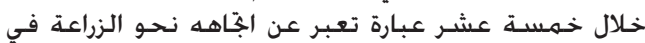

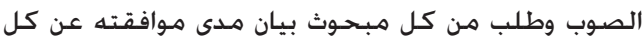

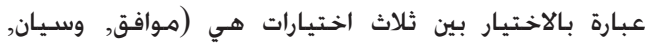

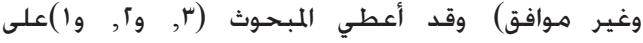

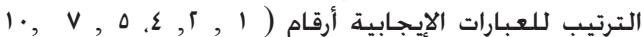

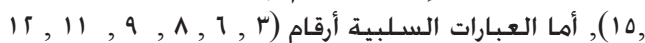

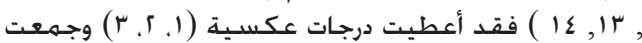
الدرجات التي حصل عليها المبحوث لتعبر عن هذا المتغير.

1ا-الاخذ بمبدأ التخطيط : تم قياس هذا المتغير من خلال عشـر

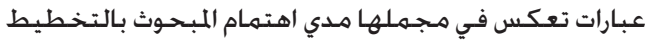

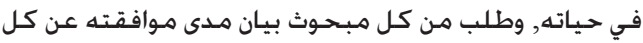
عبارة بالاختيار بين ثلاث اختيارات هي (موافقر وسيان وسيان,

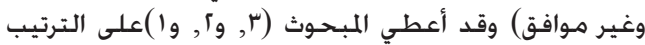

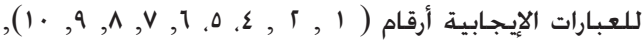

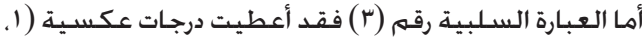

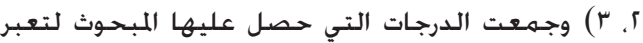
عن هذا المتغير.

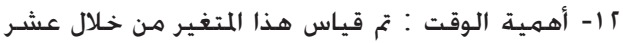

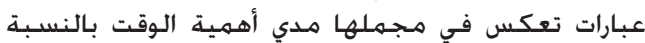

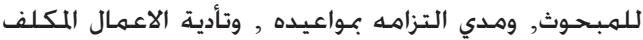

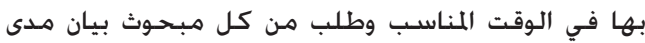

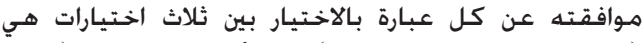

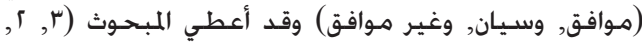

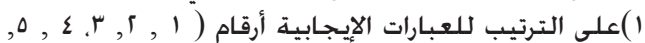

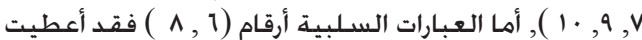

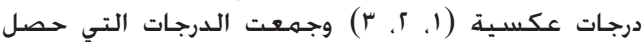
عليها المبحوث لتعبر عن هذا المتغير.

با ا- دافعية الإبناز: قيس هذا المتغير من خلال سـؤال المبحوث

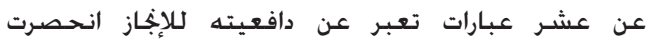

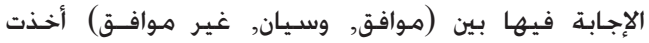

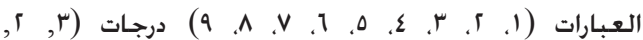

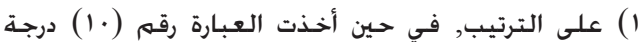

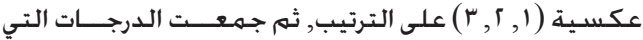
حصل عليها المبحوث لتعبر عن هذا المتغير

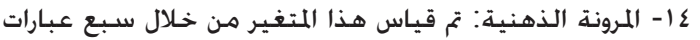

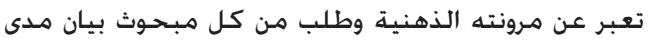

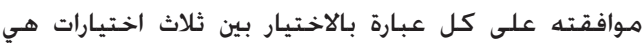

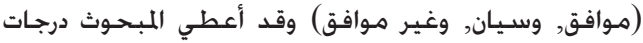

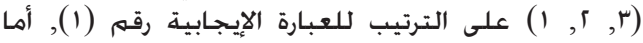

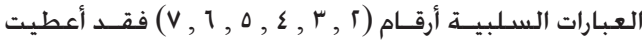

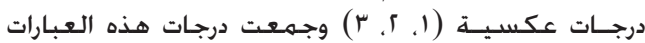
لتعبر عن هذا المتغير.

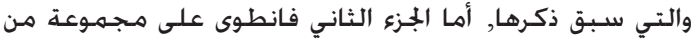

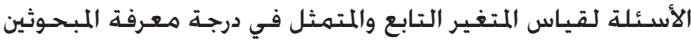

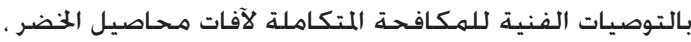

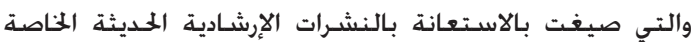

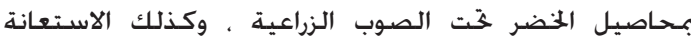

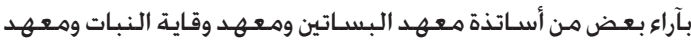

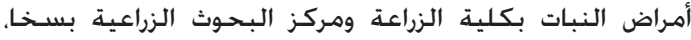

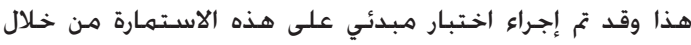

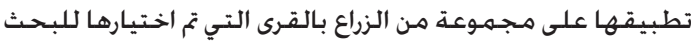

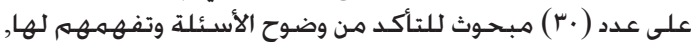

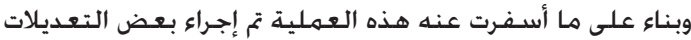

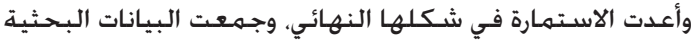

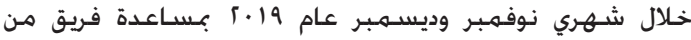

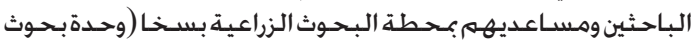

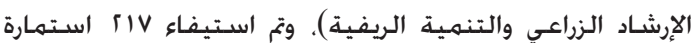

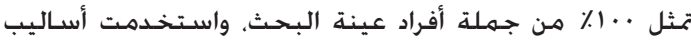

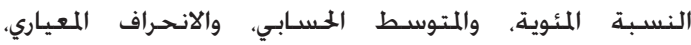
والمدى، ومعاملي الارتباط البسيط والمتعدد، ومعاملي الانحدار

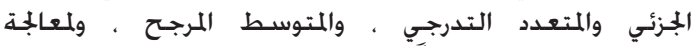

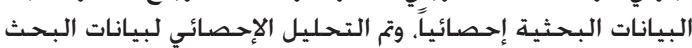

SPSS باستخــدام برنامج

سـادساً: المعالجة الكمية لبعض المتغيرات المتضمنة في البحث: (أ) قياس المتغيرات المستقلة:

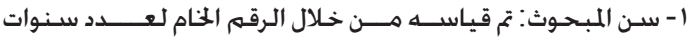

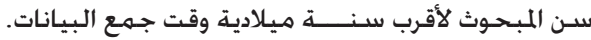

ז- درجة تعليه المبحـوث : تم قياس هذا المتغير بسؤوال المبحوث

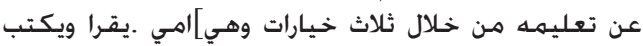

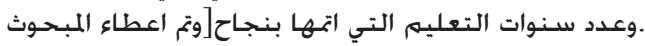

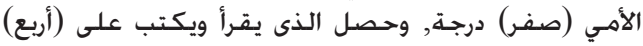
درجات، والمتعلم (درجة واحدة) عن كل سـنة تعليمية اجتازها

بنجاح.

r- التفرغ للعمل في الصـوب: وقيس هذا المتغير بسـؤال المبحـوث

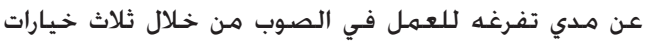

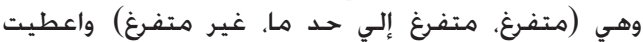

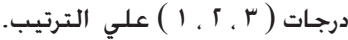

ع- عدد الصوب: قيس من خلال الرقم الخام لعدد الصوب التي يحهوزها المبحوث وقت جهمع البيانات .

ه- عدد سـنوات انشـاء الصوبة : تم قياسـه من خلال الرقهم الخام للعدد الســوات التي مرت على إنشـاء الصوبة.

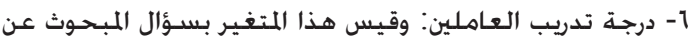

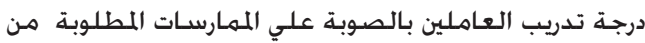

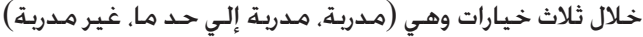
واعطيت درجات (ب, آ، أ) علي الترتيب.

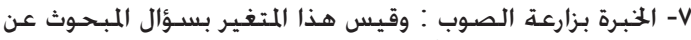

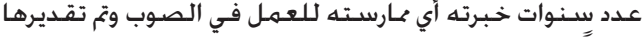
رقمياً بعدد السـنوات.

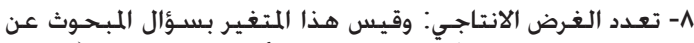

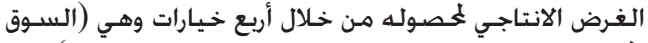

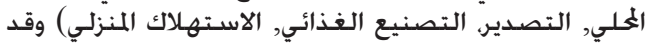

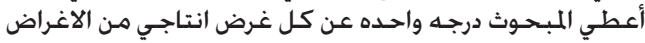

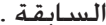

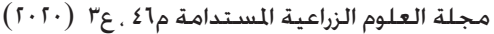




\section{النتائج ومناقشتنها}

أولاً: الخصائص المـميزة للمبـحـوثين بمنطقة البحـث:

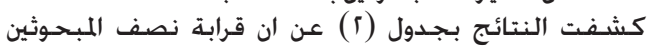
(٪८9,^)

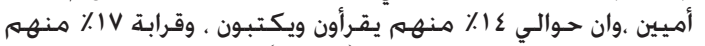

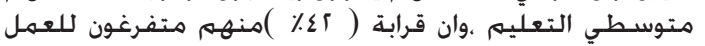

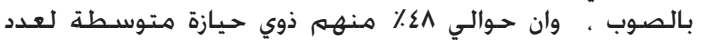

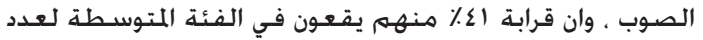

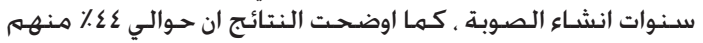

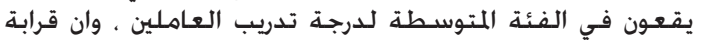

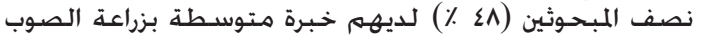

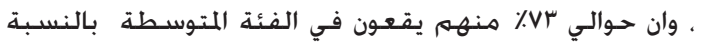

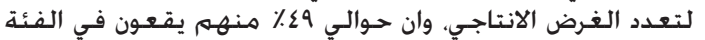

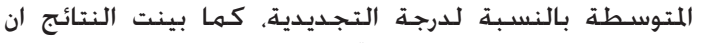

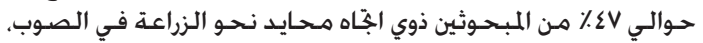

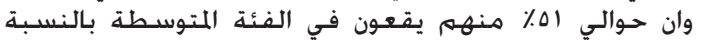

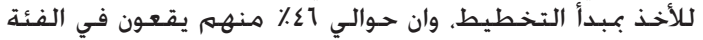

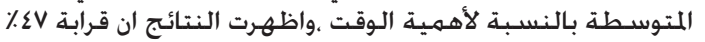

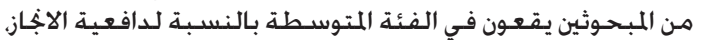

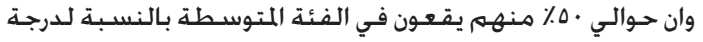

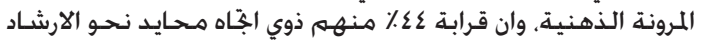
الزراعي.

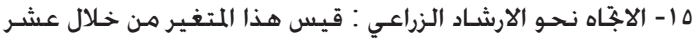

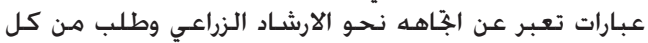

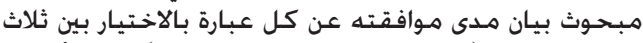

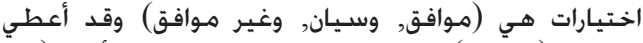

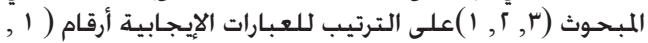

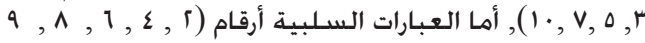

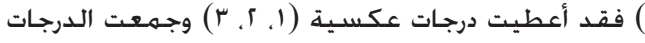

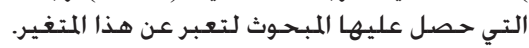

(ب) قياس المتغير التابع:والمتمثل في درجـة معرفة المبحـوثين

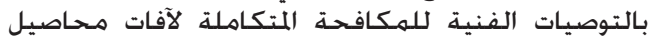

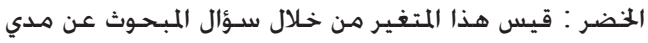

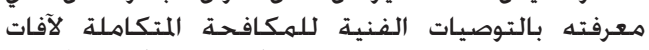

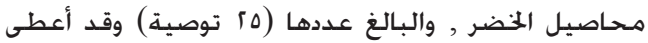

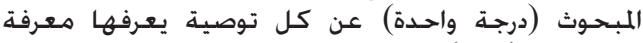

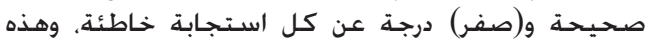

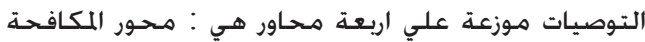

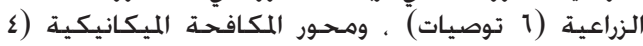

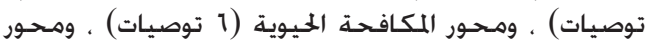

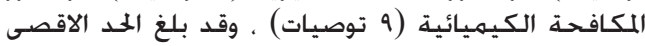

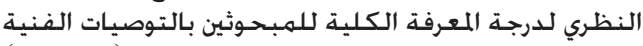

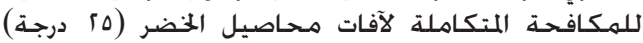

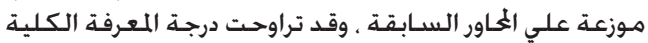

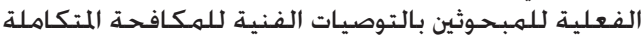

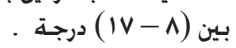

جدول ץ. توزيع المبحوثين وفقا لبعض خصائصهم المميزة

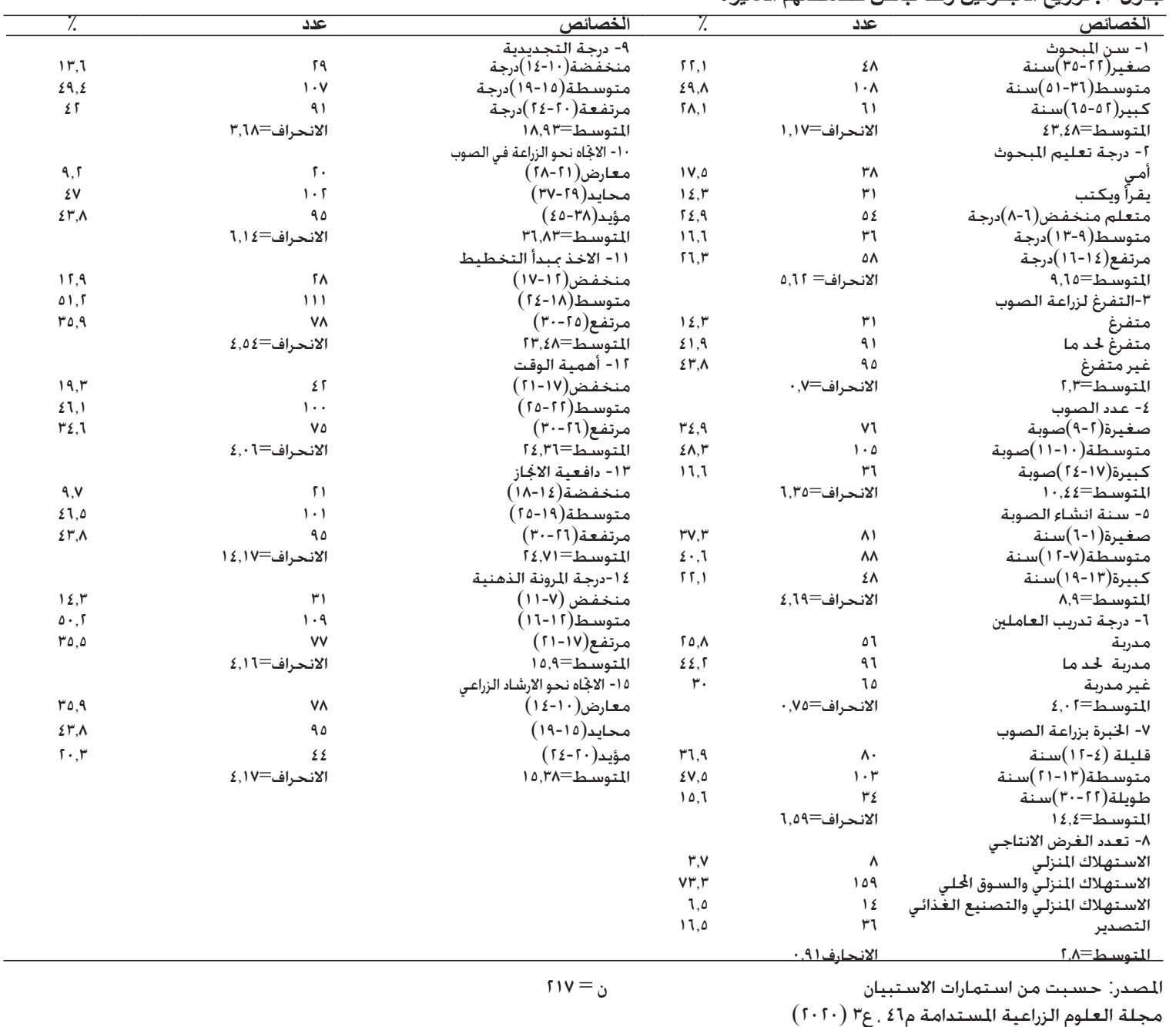




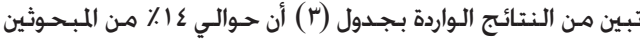

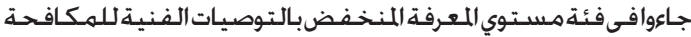

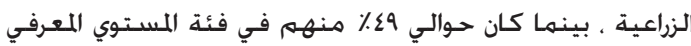

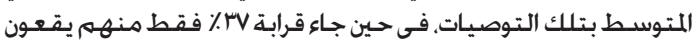

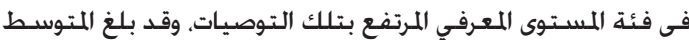

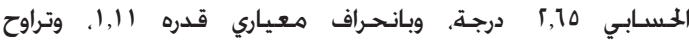

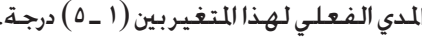

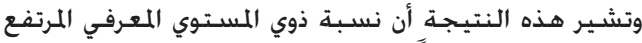

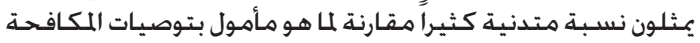

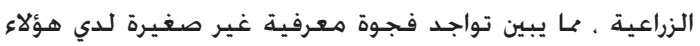

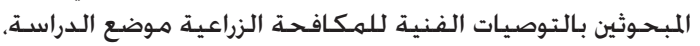

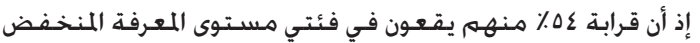

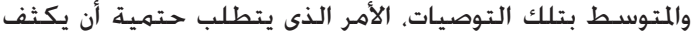

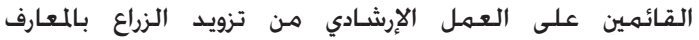

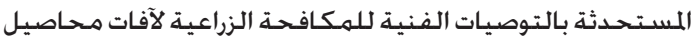

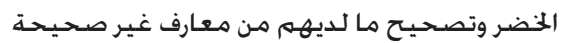
ولمزيد من الإيضاح نستعرض كل توصية من التوصيات الفنية

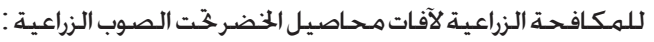

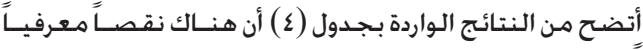

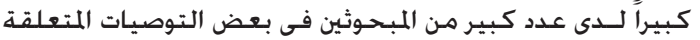

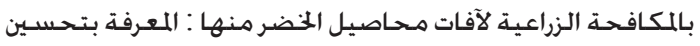

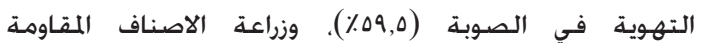

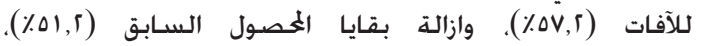

ثانياً: مستوى معرفة المبحوثين بالتوصيات الفنية للمكافحة المتكاملة لآفات محاصيل الخضضر:

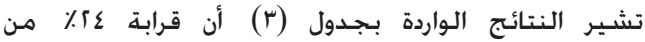

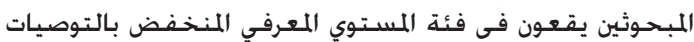

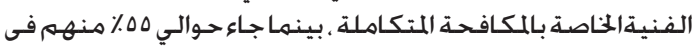

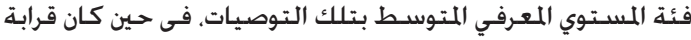

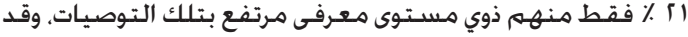

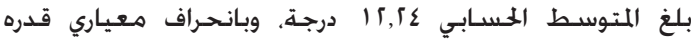

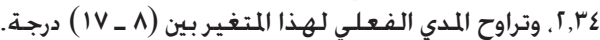

وتوضح هذه النتيجـة أن المبحـوثين ذوي المستوي المعـرفي

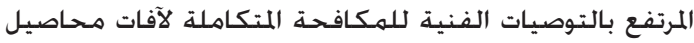

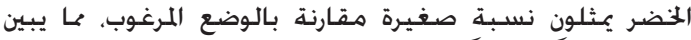

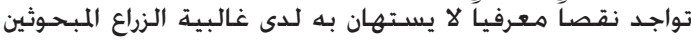

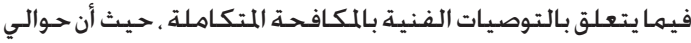

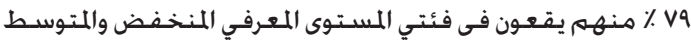

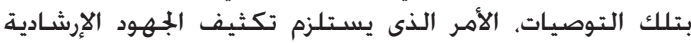

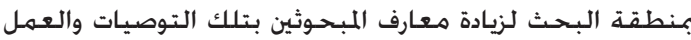

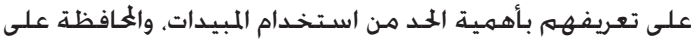

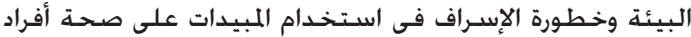

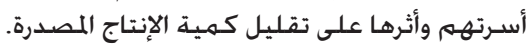

ولمزيد من الإيضاح سـوف نتناول معرفة المبحوثين

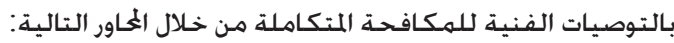

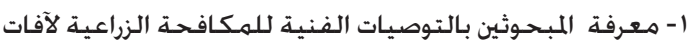

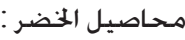

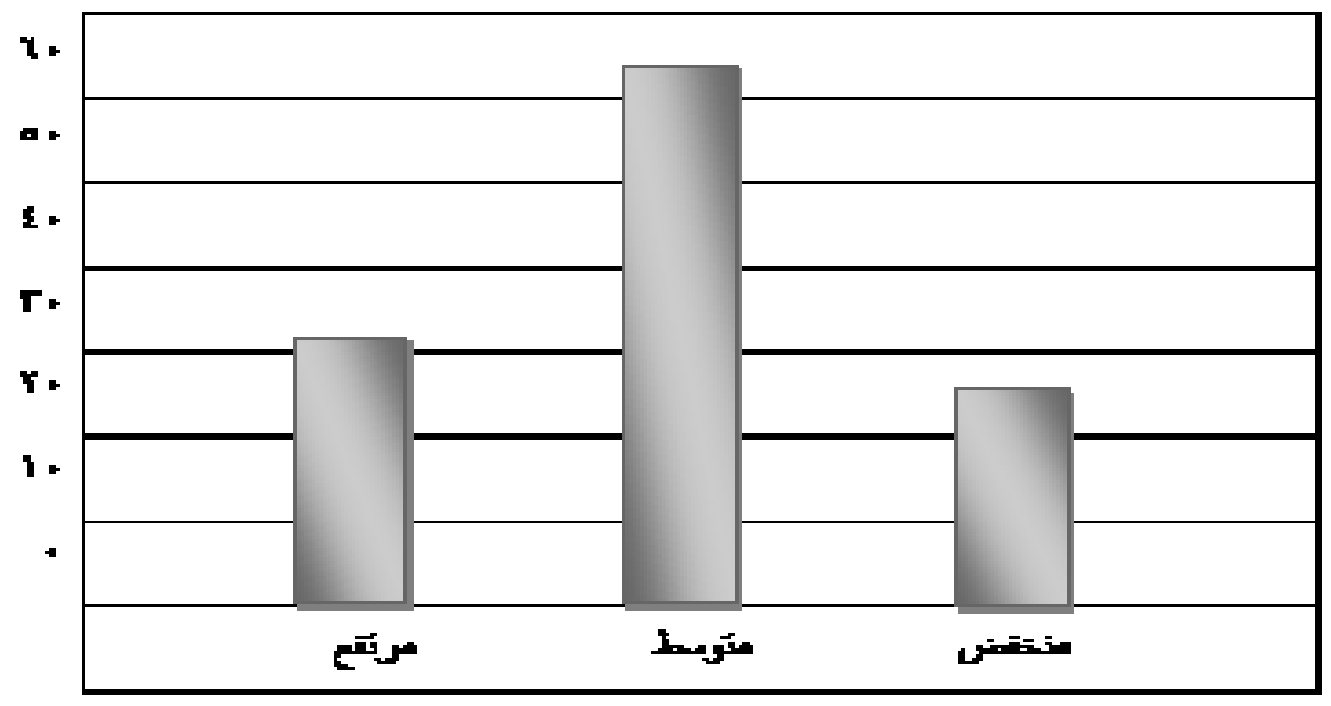

شكل ا ـ توزيع المبحوثين وفقاً لمستوى معرفتهم بالتوصيات الفنية للمكافحة المتكاملة لآفات محاصيل الخضر .

جدول ب. توزيع المبحوثين وفقاً لارجة معرفتهم بالتوصيات الفنية للمكافحة الزراعية لآفات محاصيل الخضر

\begin{tabular}{|c|c|c|}
\hline$\%$ & $ت$ & مستوى المعرفة \\
\hline $\mid \varepsilon, r$ & ו & منخفض (اقل من +) درجة \\
\hline$\varepsilon 9, r$ & $1 \cdot v$ & متوسط (r - r) درجة \\
\hline$r 1,0$ & vq & مرتفع (ع - ه) درجـة \\
\hline $1 \ldots$ & riv & الحملة \\
\hline
\end{tabular}


معرفية غير صغيرة لدي هؤلاء المبحـوثين بالتوصيات الفنية

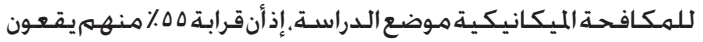

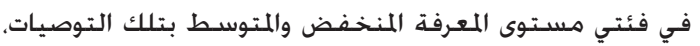

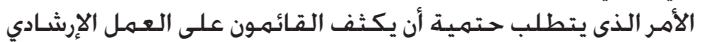

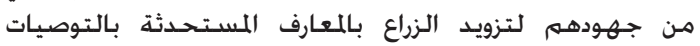

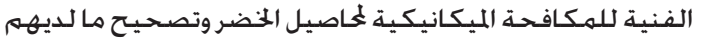
من معارف خاطئة.

ولمزيد من الإيضاح نسـتعرض كل توصية من التوصيات

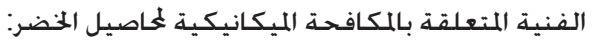

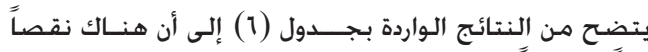

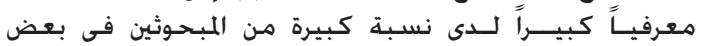

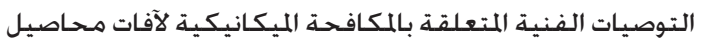

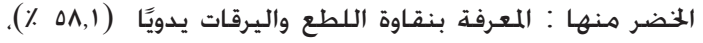

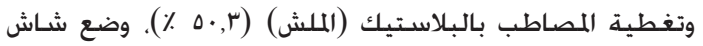

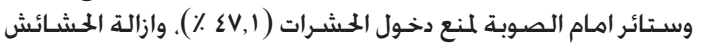

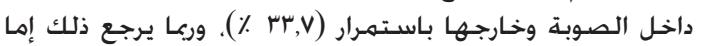

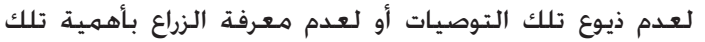

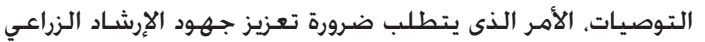

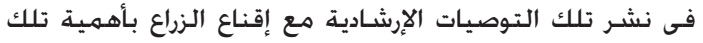

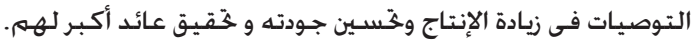

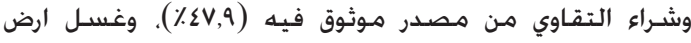

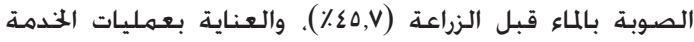

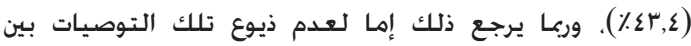

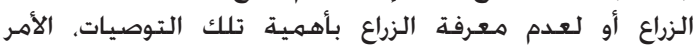

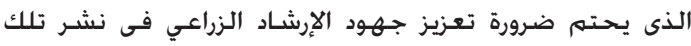

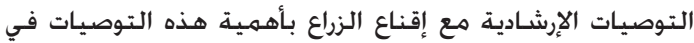

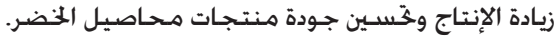

ז- معرفة المبحـوثين بالتوصيات الفنيـة للمكافحة الميكانيكية لآفات محاصيل الخضر:

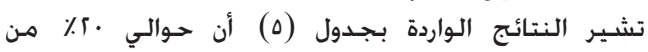

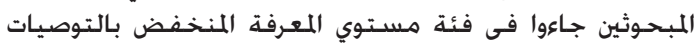

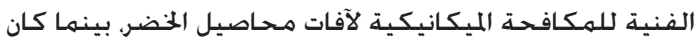

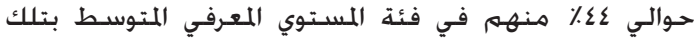

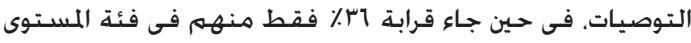

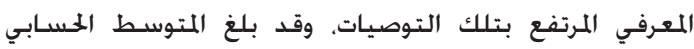

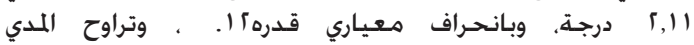

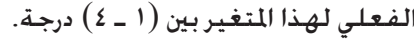

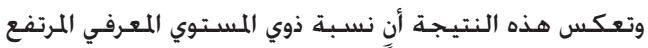

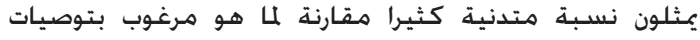

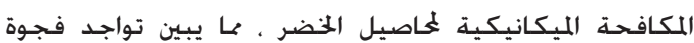

جدول ع. توزيع المبحوثين وفقاً لمعرفتهم بالتوصيات الفنية للمكافحة الزراعية لآفات محاصيل الخضر

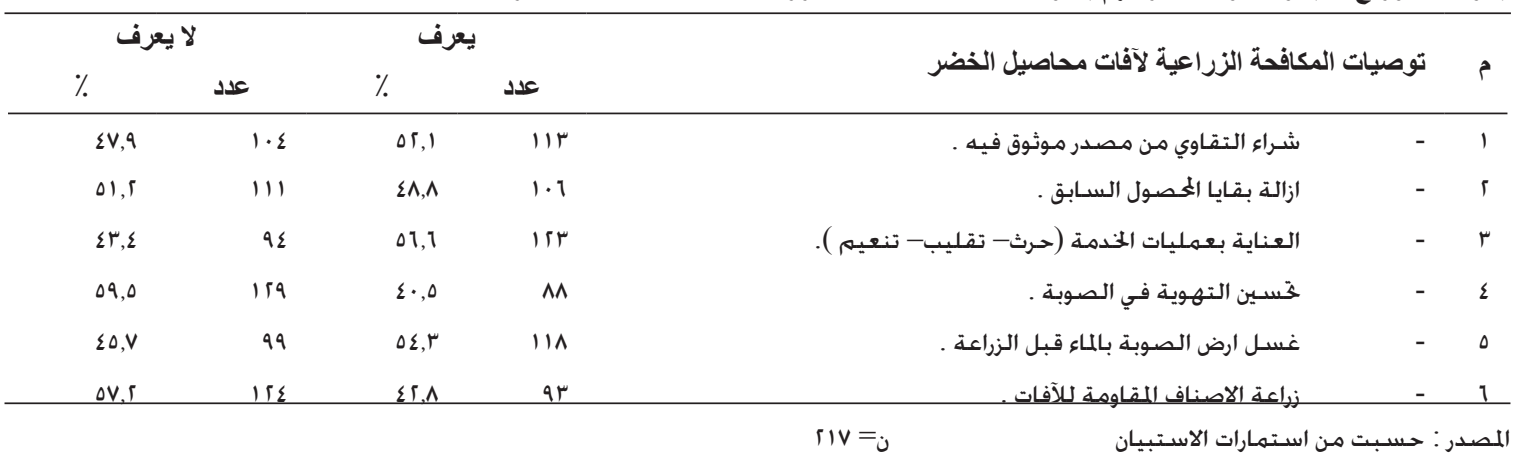

جدول •. توزيع المبحوثين وفقاً لمستوى معرفتهم بالتوصيات الفنية للمكافحة الميكانيكية لآفات محاصيل الخضر

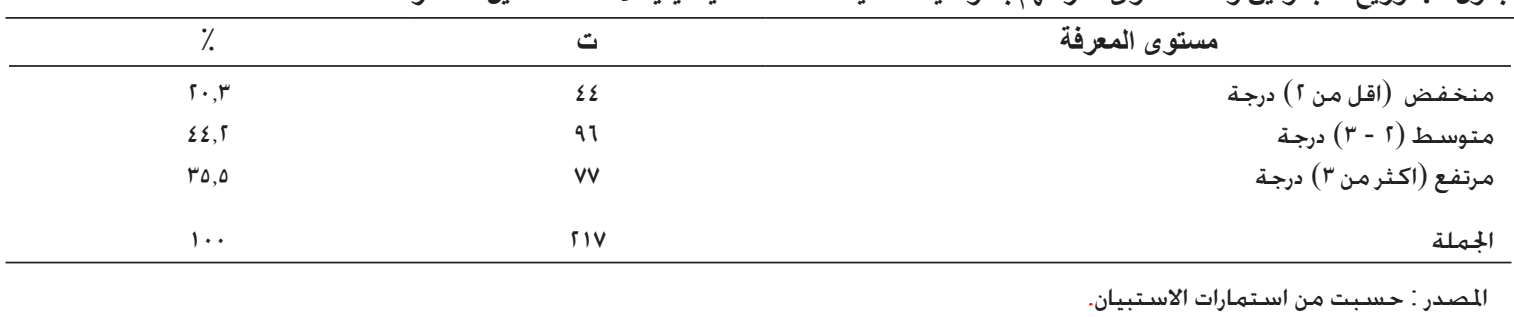

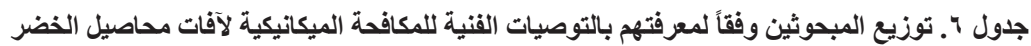

\begin{tabular}{|c|c|c|c|c|c|c|}
\hline \multicolumn{2}{|c|}{ ل ل الا يعرف } & \multicolumn{2}{|c|}{ 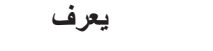 } & \multirow{2}{*}{\multicolumn{2}{|c|}{ توصيات المكافحة الميكانيكية لآفات محاصيل الخضر }} & \multirow{2}{*}{ م } \\
\hline$\%$ & عدد & $\%$ & عدد & & & \\
\hline $\mathrm{rr}, \mathrm{v}$ & $v^{r}$ & $11, r$ & $1 \leq \varepsilon$ & ازالة الحـشـائش داخـل الصـوبـة وخـارجهـا بـاســـــرار . & - & 1 \\
\hline$\Delta \wedge, 1$ & 151 & $\sum 1,9$ & 91 & نقاوة اللطع واليرقات يدويا . & - & r \\
\hline$\Delta \cdot, r$ & 1.9 & $\Sigma 9, V$ & $1 \cdot 1$ & تغطية المصاطب بالبلاستيك ( الملش ). & - & r \\
\hline
\end{tabular}




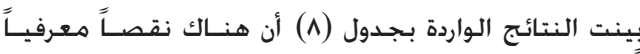

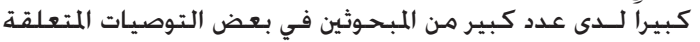

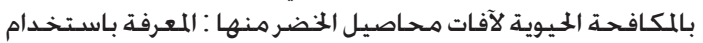

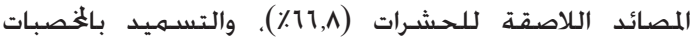

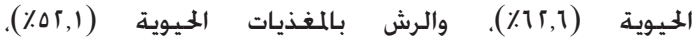

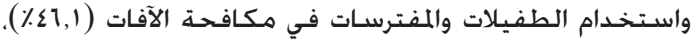

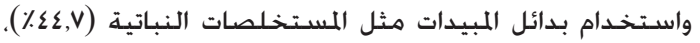

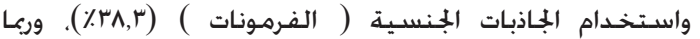

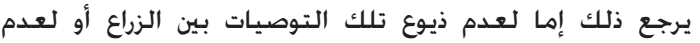

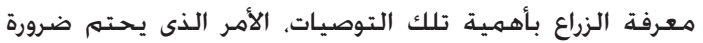

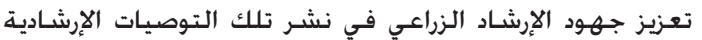
مع إقناع الزراع بأهمية هذه التوصيات في زيادة الإنتاج وختسين تلاعني جودة منتجات محاصيل الخضر.

ع- معرفة المبحوثين بالتوصيات الفنية للمكافحة الكيميائية لآفات

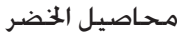

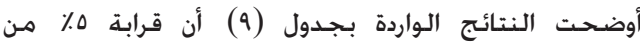

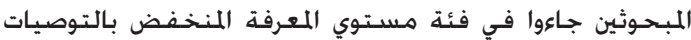

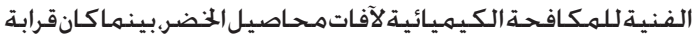

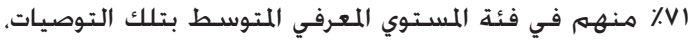

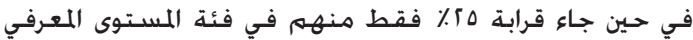

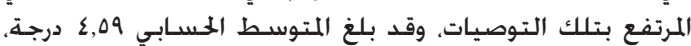

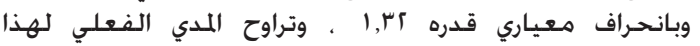
المتغير بين (1 ـ 1 ) درجة. r- معرفة المبحوثين بالتوصيات الفنية للمكافحـة الحيوية لآفات

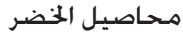

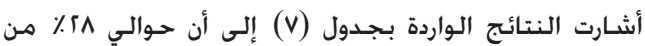

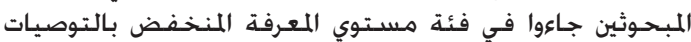

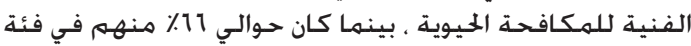

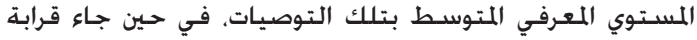

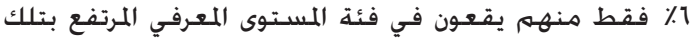

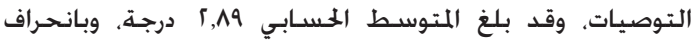

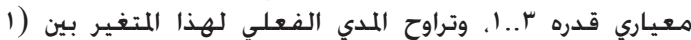

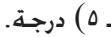

وتشير هذه النتيجـة أن نسبة ذوي المستـوي المعرفي المرتفع

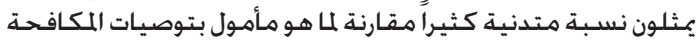

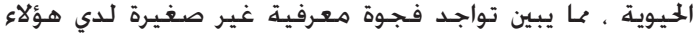

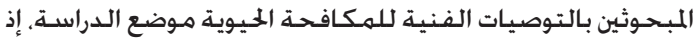

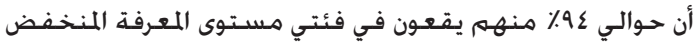

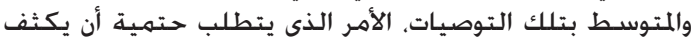

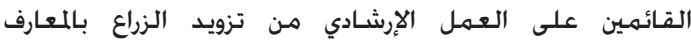

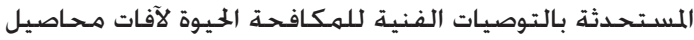

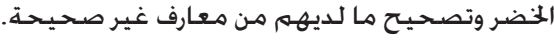

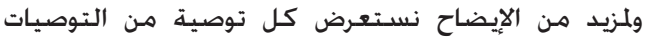

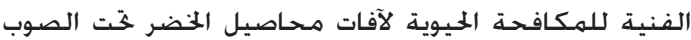

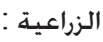

جدول V. توزيع المبحوثين وفقاً للدجة معرفتهم بالتوصيات الفنية للمكافحة الحيوية لآفات محاصيل الخضر

\begin{tabular}{|c|c|c|}
\hline$\%$ & $ت$ & مستوى المعرفة \\
\hline$[\Lambda, 1$ & 11 & منخفض (1- r) درجة \\
\hline $11, r$ & $1 \varepsilon \varepsilon$ & متوسط (r - ع) درجة \\
\hline 0,1 & ir & مرتفع (ه - 1) درجة \\
\hline $1 .$. & riv & الجملة \\
\hline
\end{tabular}

المصدر : حسبت من استمارات الاستبيان

جدول ^. توزيع المبحوثين وفقاً لمعرفتهر بالتوصيات الفنية للمكافحة الحيوية لآفات محاصيل الخضر

\begin{tabular}{|c|c|c|c|c|c|c|}
\hline \multicolumn{2}{|c|}{ ل الا يعرف } & \multicolumn{2}{|c|}{ 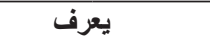 } & \multirow{2}{*}{\multicolumn{2}{|c|}{ توصيات المكافحة الحيوية لآفات محاصيل الخضر }} & \\
\hline$\%$ & عدد & $\%$ & عدد & & & \\
\hline$\varepsilon \varepsilon, V$ & $9 \mathrm{~V}$ & $\Delta \Delta, r$ & $1 \Gamma$ & استـخدام بدائل المبيدات مثل المستخلصات النباتية . & - & 1 \\
\hline$\Delta r, 1$ & $11 \%$ & $\sum v, q$ & $1 \cdot \varepsilon$ & الرش بالمغذيات الحيوية . & - & r \\
\hline $11, \wedge$ & $1 \leq 0$ & 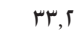 & vi & اسـتخــام المصائد اللاصقة للحشـرات . & - & r \\
\hline $1 \Gamma, 1$ & $1+1$ & $r v, \varepsilon$ & $\wedge 1$ & التسـميد بالخصبات المبوية . & - & $\varepsilon$ \\
\hline$\varepsilon 1,1$ & $1 \cdots$ & $r 0,9$ & $11 \mathrm{~V}$ & استـخـدام الطفيلات والمفترسـات في مكافحـة الآفات . & - & 0 \\
\hline$r \Lambda, r$ & ar & $11, \mathrm{~V}$ & $1 r \varepsilon$ & استخـدام الجلاذبات الجنسية ( الفرمونات) ) & & \\
\hline
\end{tabular}

جدول 9 . توزيع المبحوثين وفقاً لمستوى معرفتهم بالتوصيات الفنية للمكافحة الكيميائية لآفات محاصيل الخضر

\begin{tabular}{|c|c|c|}
\hline$\%$ & $ت$ & مستوى المعرفة \\
\hline$\varepsilon, 1$ & 1. & منخفض (1- r) درجـة \\
\hline$v \cdot, q$ & $10 \varepsilon$ & متوسط (r - ه) درجـة \\
\hline$i \varepsilon, 0$ & or & مرتفع (1) - v درجة \\
\hline $1 \ldots$ & riv & الجمملة \\
\hline
\end{tabular}

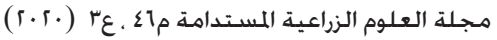




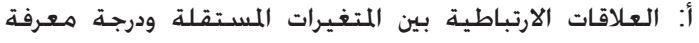

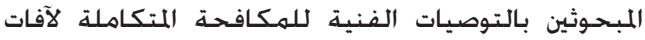

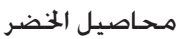

يتوقع الفـرض البحثـي الأول وجـود عـلاقة ارتباطية معنـوية بين

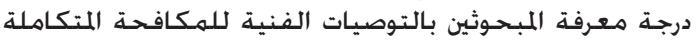

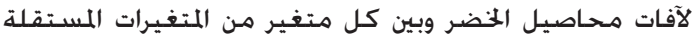

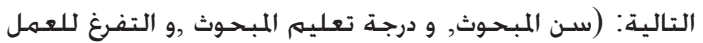

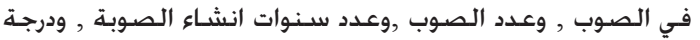

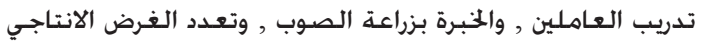

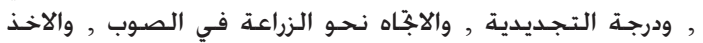

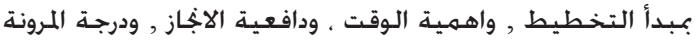

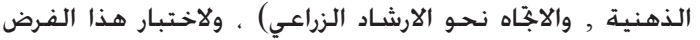

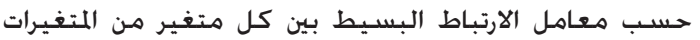

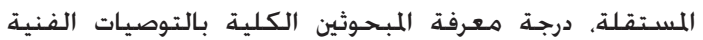

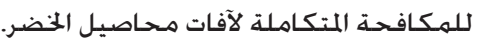

أشـارت النتائج الواردة بـجدول (11) إلى وجـود علاقة ارتباطية

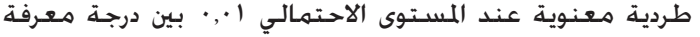

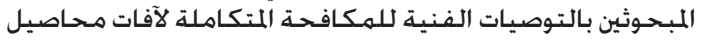

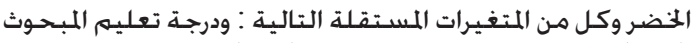

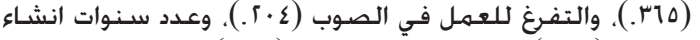

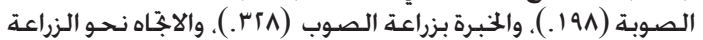

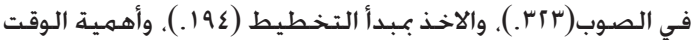

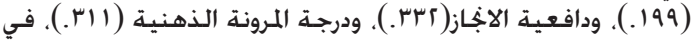

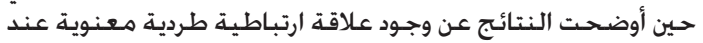

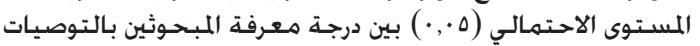

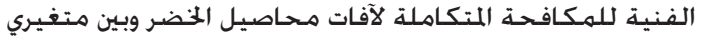

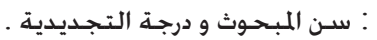

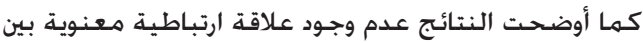

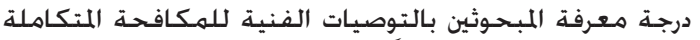

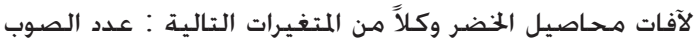

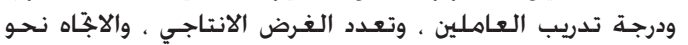

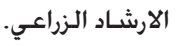

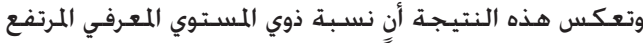

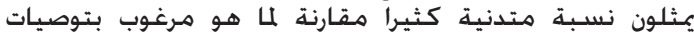

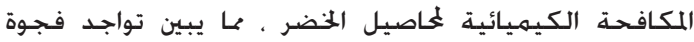

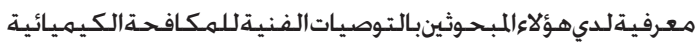

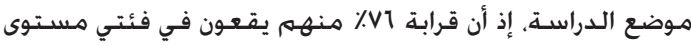

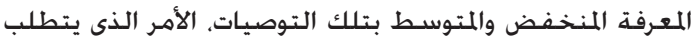

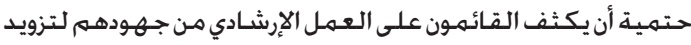

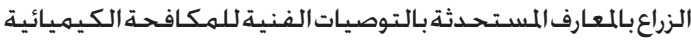
لعاصيل الخضر وتصـيـح ما لديهمه من معارف خـاطئة.

ولمزيد من الإيضاح نسـتعرض كل توصية من التوصيات

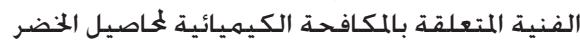

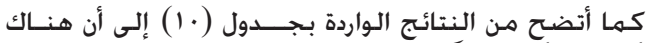

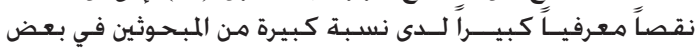

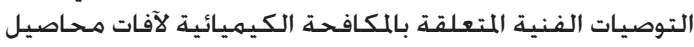

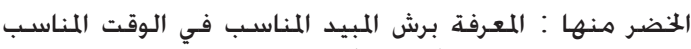

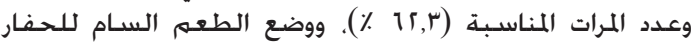

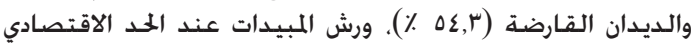

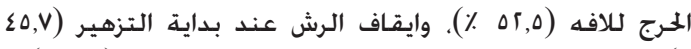

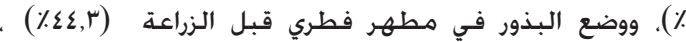

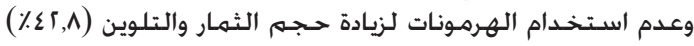

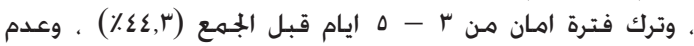

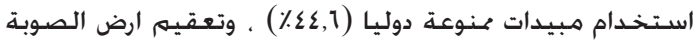

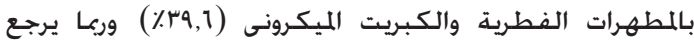

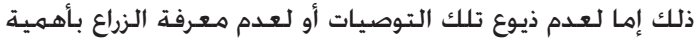

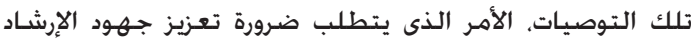

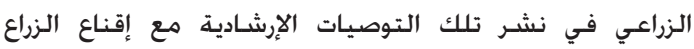

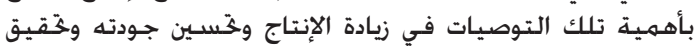

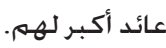

ثالثًا: العلاقات الارتباطية وتفسير التباين بين درجـة معرفة

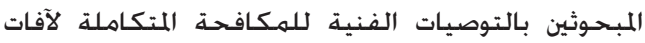
محاصيل الخضر

جدول ا . توزيع المبحوثين وفقاً لمعرفتهم بالتوصيات الفنية للمكافحة الكيميائية لآفات محاصيل الخضر

\begin{tabular}{|c|c|c|c|c|c|}
\hline \multicolumn{2}{|c|}{ لا يعرف } & \multicolumn{2}{|c|}{ يعرف } & \multirow{2}{*}{ توصيات المكافحة الكيميائية لآفات محاصيل الخضر } & \multirow{2}{*}{ r } \\
\hline$\%$ & عدد & $\%$ & عدد & & \\
\hline$\varepsilon \varepsilon, r$ & 91 & $\Delta \Delta, V$ & 151 & وضع البذور في مطهـر فطري قبل الزراعة . & 1 \\
\hline$r 9,1$ & $\wedge 1$ & $1 \cdot, \Sigma$ & $|r|$ & تعقيهم ارض الصـوبـة بالمطهرات الفـرية والكبريت الميكرونى . & r \\
\hline$\Delta \varepsilon, r$ & 111 & $\Sigma \Delta, 1$ & 99 & وضع الطعـم السـام للحفـار والديدان القـارضـة . & r \\
\hline$\Delta \Gamma, \Delta$ & $11 \varepsilon$ & $\Sigma V, 0$ & $1 . r$ & رش المبيدات عند الحـد الاقتصـادي الحـرج للافــ . & $\varepsilon$ \\
\hline$\varepsilon \varepsilon, r$ & 91 & $\Delta \Delta, V$ & 151 & ترك فترة امان من ب - ه ايام قبل الجهمع . & $\Delta$ \\
\hline$\varepsilon \Delta, V$ & 99 & $r \varepsilon, r$ & 111 & ايقاف الرش عند بداية التزهير . & 1 \\
\hline $1 r, r$ & ro & $r v, v$ & $\Lambda r$ & رش المبيد المناسـب في الوقت المناسـب وعدد مرات مناسبـة . & v \\
\hline$\Sigma \Gamma, \Lambda$ & 94 & $\Delta \mathrm{V}, \mathrm{r}$ & $1 \Gamma \varepsilon$ & عـدم اسـتخـدام الهـرمونات لزيادة حـــم الثمـار والتلوين. & $\wedge$ \\
\hline$\varepsilon \cdot, 1$ & $\Lambda \Lambda$ & $\Delta 9, \varepsilon$ & 159 & عدم استخــدام مبيدات مينوعة دوليا . & 9 \\
\hline
\end{tabular}


جدول ال ـ نتائج العلاقات الارتباطية والاتحدارية بين المتغيرات المستقلة ودرجة معرفة المبحوثين بالتوصيات الفنية للمكافحة المتكاملة لآفات محاصيل الخضر

\begin{tabular}{|c|c|c|c|c|c|}
\hline قيمة (ت) & معامل الاتحدار الجزئي & معامل الاتحدار الجزئي & الارتباط البسيط & المتغيرات المستقلة & b \\
\hline.$\Sigma 95$ & ..rT & $\ldots 1$ & $* .1 \leq V$ & سـن المبحـوث & 1 \\
\hline$* * .1 r, r$ &.$r \cdot V$ &. .9 & **. rro & درجـة تعليم المبحـوث & r \\
\hline.$\wedge \vee \wedge$ &. .09 &. $\ln$ & $* * . r \cdot \varepsilon$ & التفـرغ للعـمل في الصـوب & $r$ \\
\hline .491 & ..ro & $\ldots 9$ &. .10 & عدد الصوب & $\varepsilon$ \\
\hline$r 90,1$ &. $.9 \varepsilon$ &..$r \Delta$ & $* * .191$ & عدد ســـوات انشـاء الصـوبـة & 0 \\
\hline$\cdot 1 \wedge, 1$ & .11 & $.19 \varepsilon$ &..$r v$ & درجـة تدريب العاملين & 1 \\
\hline$* \ldots v, r$ & $.1 \leqslant r$ &.$\Sigma \wedge$ & $* * . r i \wedge$ & الخبرة بزراعة الصوب & $v$ \\
\hline$\cdot 1 r, 1$ &..$v$ & $.1 \mathrm{Vr}$ &. .11 & تعدد الغرض الانتاجي & $\wedge$ \\
\hline$\cdot v \varepsilon, 1$ &. $.1 \mathrm{~V}$ & $\ldots 11$ & $* .1 \Delta \Delta$ & درجـة التـجـديدية & 9 \\
\hline.$v a$ &. .11 &. .11 & 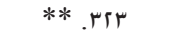 & الاجّاه نـحـو الزراعة في الصـوب & 1. \\
\hline.$\varepsilon r q$ &..$r \wedge$ &. $.1 \varepsilon$ & $* * .192$ & الأخـذ بمبـدأ التخطيط & 11 \\
\hline$\cdot 7 \mathrm{~V}, 1$ &..$v V$ &..$r \varepsilon$ & $* * .199$ & اهمية الوقت & 15 \\
\hline * rrq, r &.$|V|$ &. $.7 v$ & 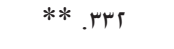 & دافعية الاجماز & ir \\
\hline * 9^1,1 &. $.1 \%$ &..$\vee \wedge$ & **. & درجـة المرونة الذهنية & $1 \varepsilon$ \\
\hline * .rts & ..r & $\ldots 1$ &. .01 & 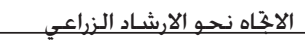 & 10 \\
\hline & & \multicolumn{2}{|c|}{ 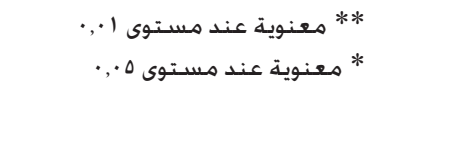 } & \multicolumn{2}{|c|}{ 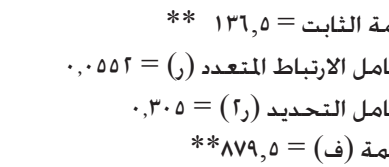 } \\
\hline
\end{tabular}

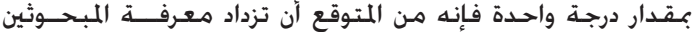

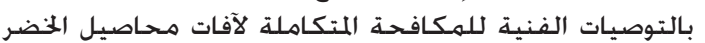
بمقدار 9. ب,. ، درجـة في ظل ديناميكية تأثير بقية المتغيرات المسـتقلة الأخـرى.

كما اتضـح أن قيمة معامل الانحـدار الجزئي لمتغير الخبرة

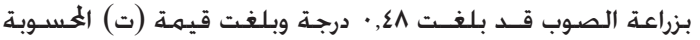

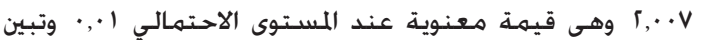

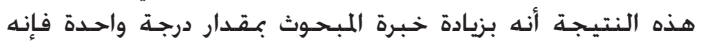

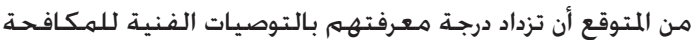

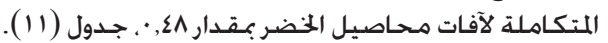

وأبرزت النتائهج بـجدول (11) أن قيمة معـامل الانحـدار الجزئي

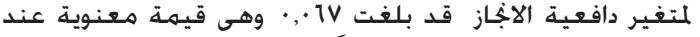

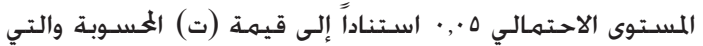

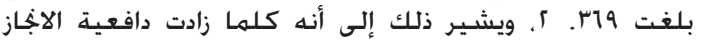

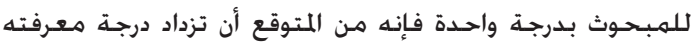

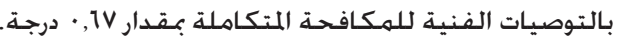

وأوضحت النتائج أن قيمة معامل الانحـدار الجـزئي لمتغير

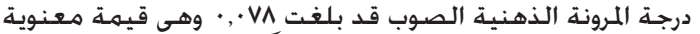

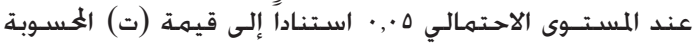

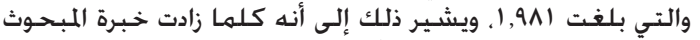

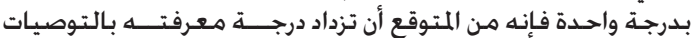

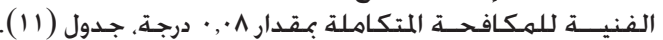

وأبرزت النتائه بـجـدول (11) أن قيمة معامل الانحـدار الجزئي

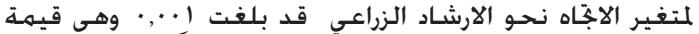

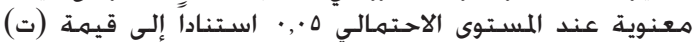

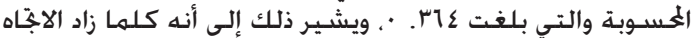

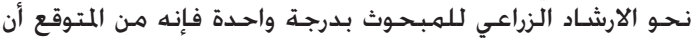

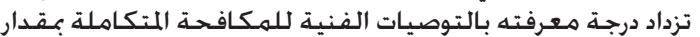

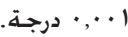

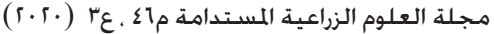

ومن العرض السـابق يمكن قبول الفرض البحثثي الأول جزئيًاً.

ب- تفـسـير التباين في درجـة معـرفــة المبـحــوثين بالتوصيات الفنيـة

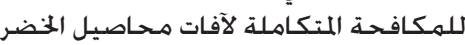

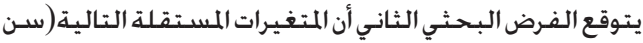

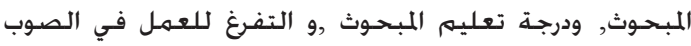

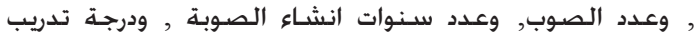

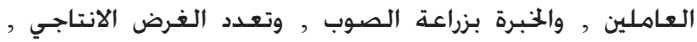

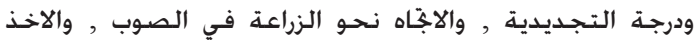

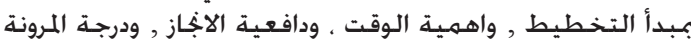

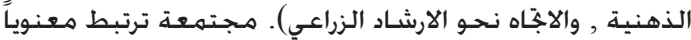

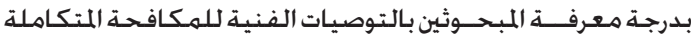
لآفات محاصيل الخضر كمـتغير تابع.

وتبين نتائسج الانحـدار الخطى المتعـدد بـجـدول (11) أن المتغيرات

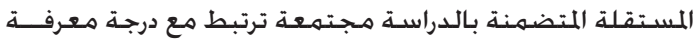

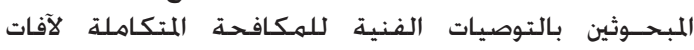

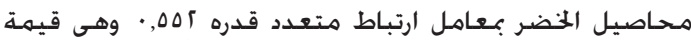

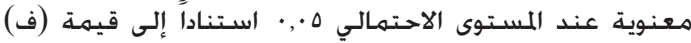

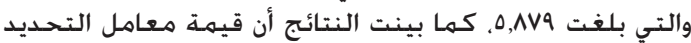

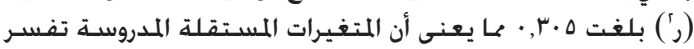

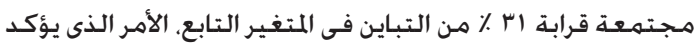

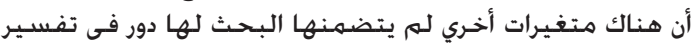

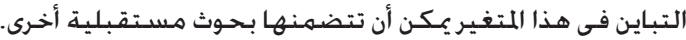

وبنـاء على ذلك يمكـن قبـول الفرض البحــي الثاني جـزئياً.

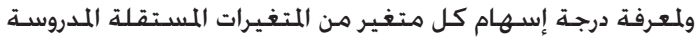

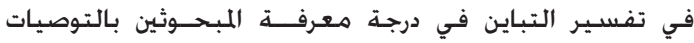

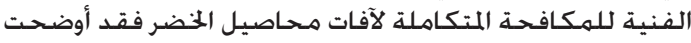

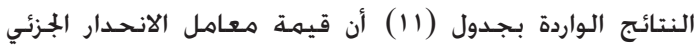

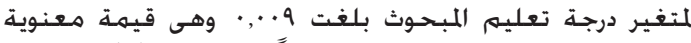

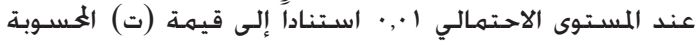

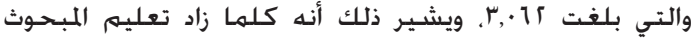


الصوب بنسبة (0,1\% (جدول I 1) ).

وبناءً على ذلك فإنه عند تخطيط البرامج الإرشادية

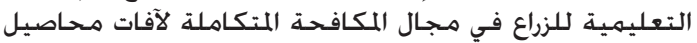

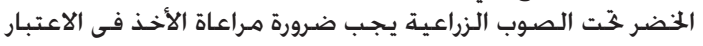

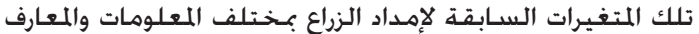

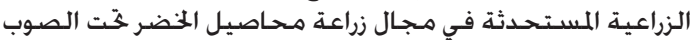

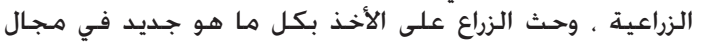

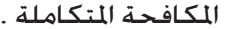

رابعاً: المشـكلات التي تواجه المبحوثين في مجال زراعة محهاصيل

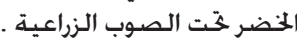

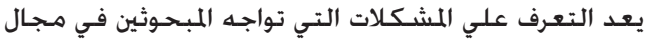

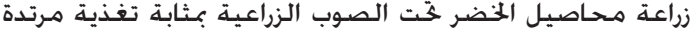

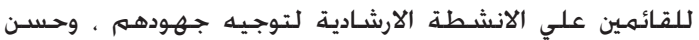

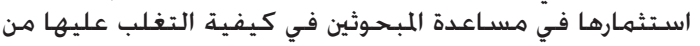

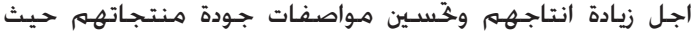

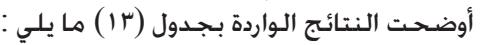

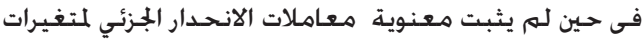

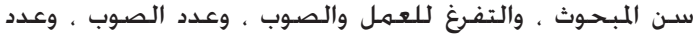

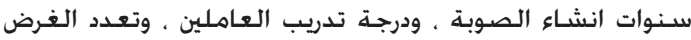

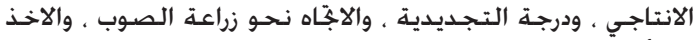

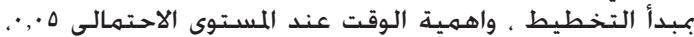

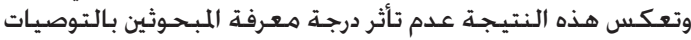

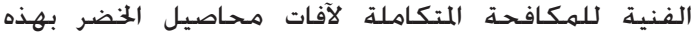

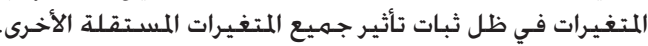
ومن خـال النتائج السـابقـة يمكن قبول الفرض البحثي الثالث

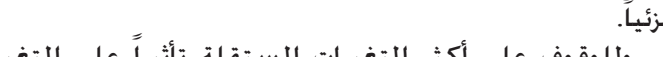
وللوقوف على أكثر المتغيرات المستقلة تأثيراً على المتغير

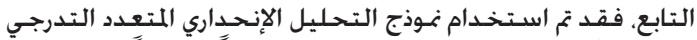

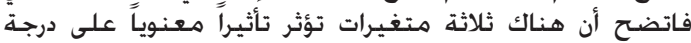

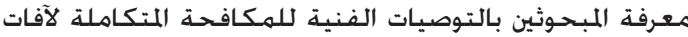

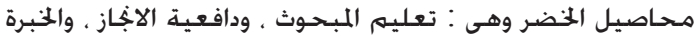

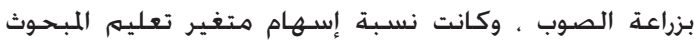

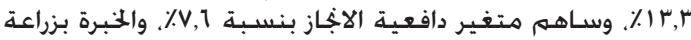

جدول r ا. نتائج النموذج المختزل للعلاقات الارتباطية والاتحدارية بين المتغيرات المستقلة ودرجة معرفة المبحوثين بالتوصيات الفنية للمكافحة المتكاملة لآفات محاصيل الخضر

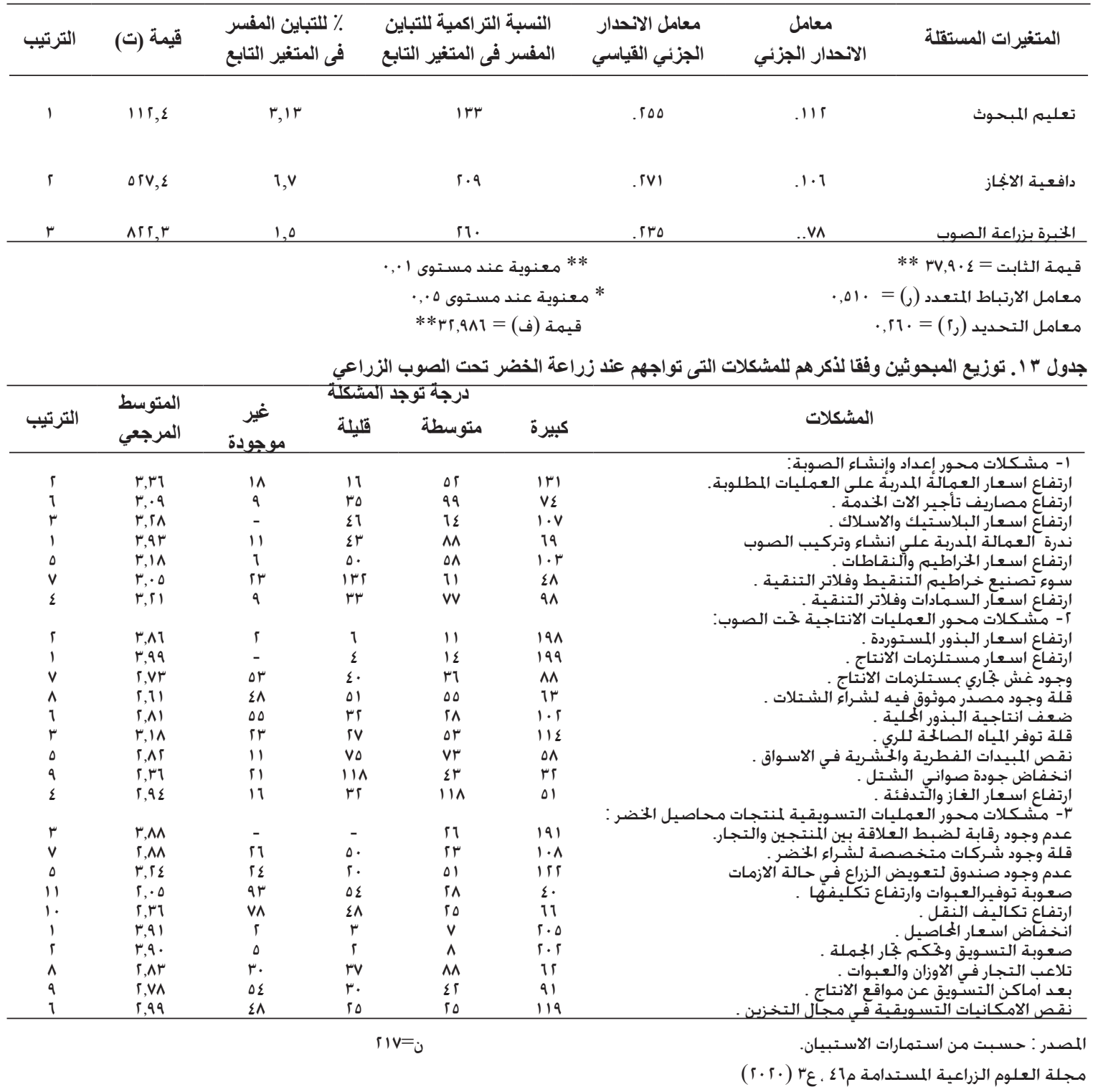


التوصيات

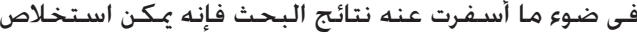

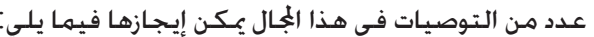

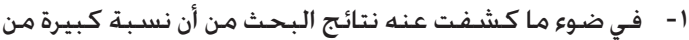

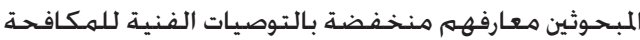

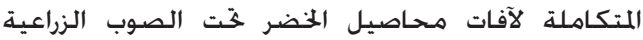

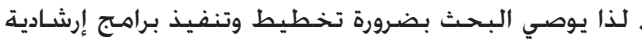

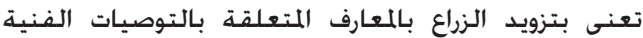

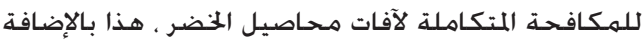

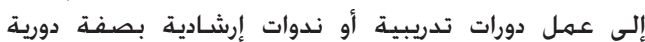

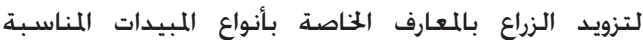

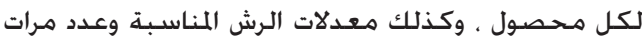

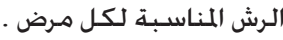

آ- ضرورة تنسيق وتكامل الجهـود الإرشادية والأجهـزة الفنية

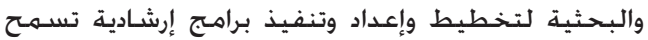

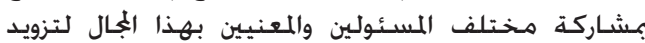

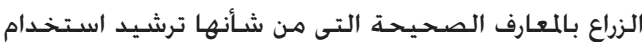
المبيدات والعحافظة على البيئة وعلى صـحـة الإنسـان.

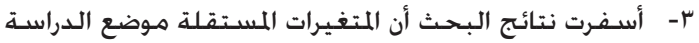

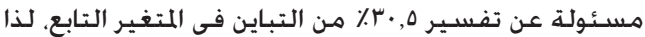

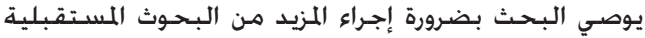

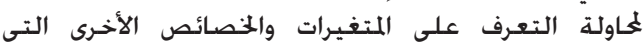

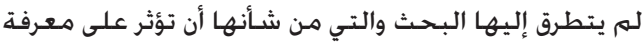

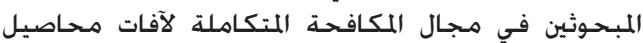
الخضر.

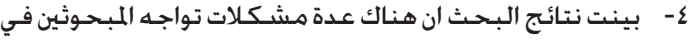

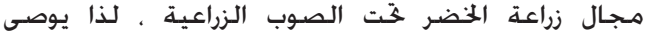

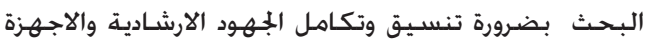

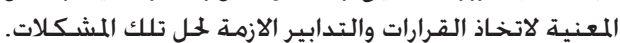

المراجع

احمد ، هـ ريم صالح (10 • م ) دراسـة تبني التوصيات التقنية

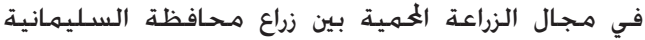

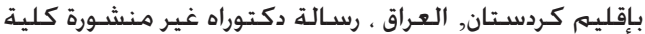

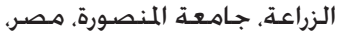

الجـندي، مـحمـد صلاح الدين (1991) العالهم العربي والتحـولات

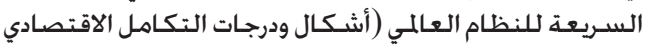

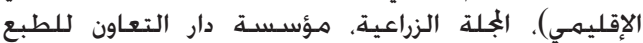

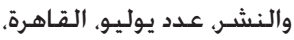

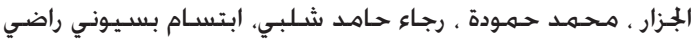

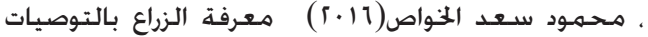

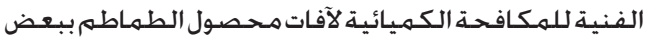

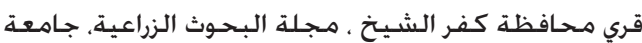

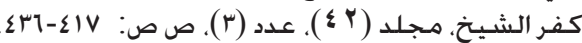

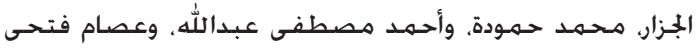

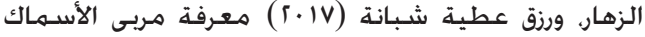

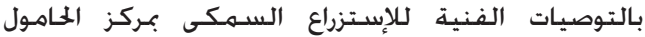

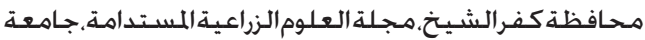

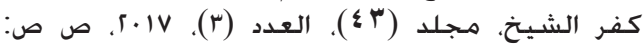
$.19-V \mu$
أ- مشـكلات مهـور إعداد وإنشـاء الصـوبة

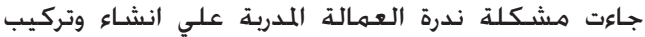

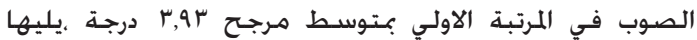

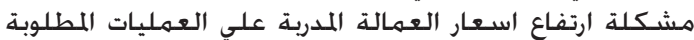

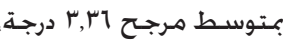

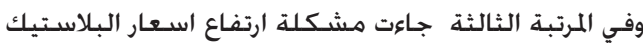

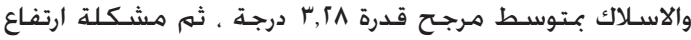

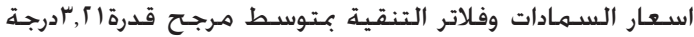

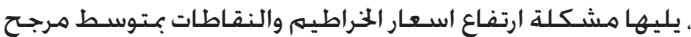

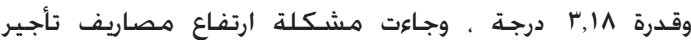

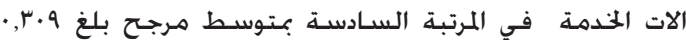

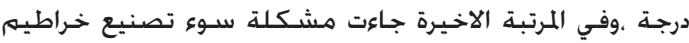

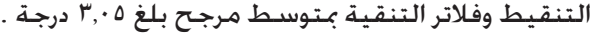

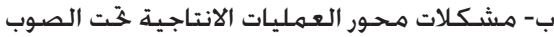

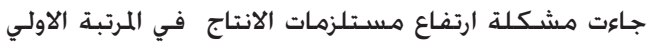

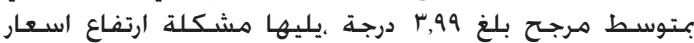

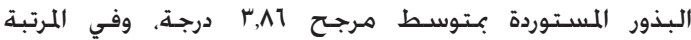

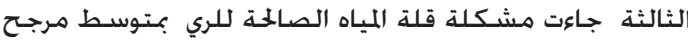

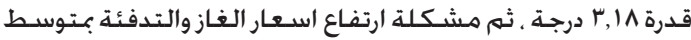

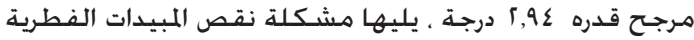

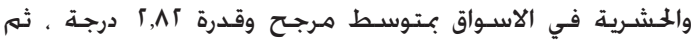

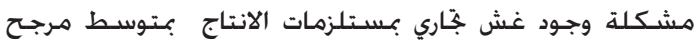

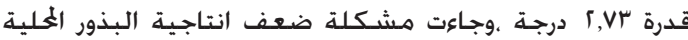

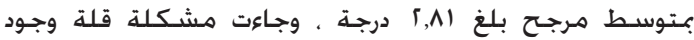

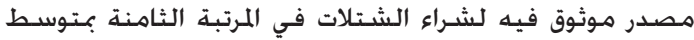

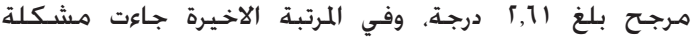

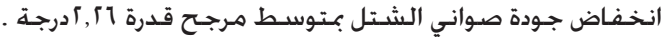

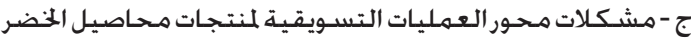

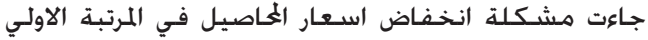

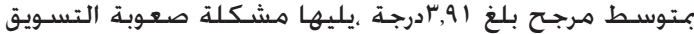

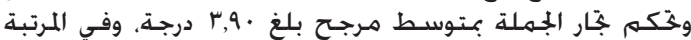

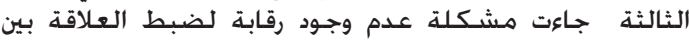

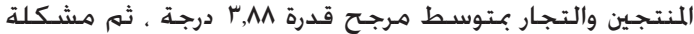

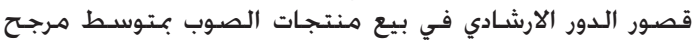

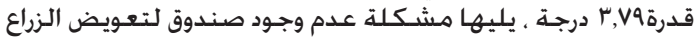

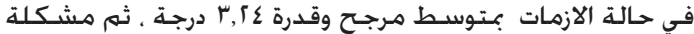

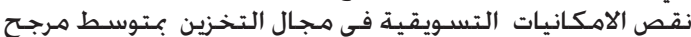

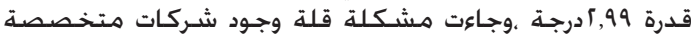

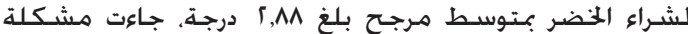

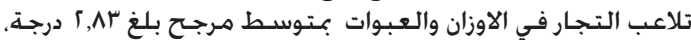

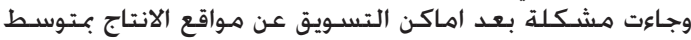

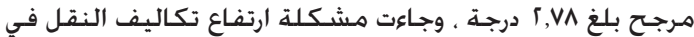

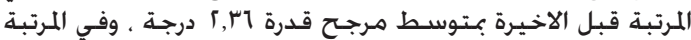

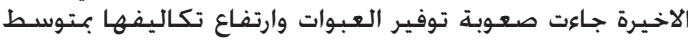
مرجـح قدرة هاعة •, أدرجة

مما سبقق يتضـح أن هنـاك عدة مشـكلات ذات أهـمية قصـوى

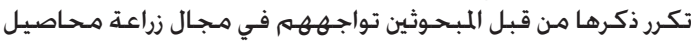

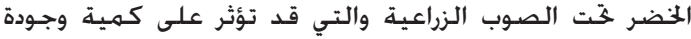

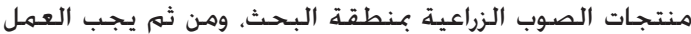

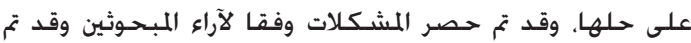

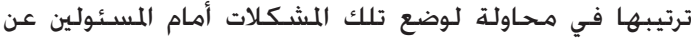

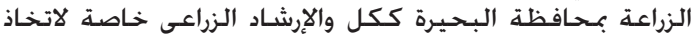

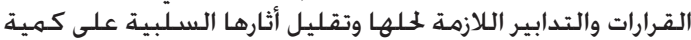

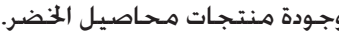

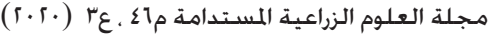




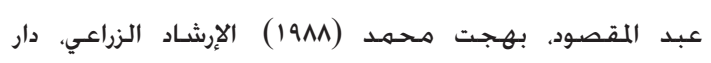
الوفاء للطباعة والنشـر والتوزيع، المنصـورة.

عمـر، أحمد محسمد (I9VA) الإرشـاد الزراعي، أوفست للطباعة،

قشـة، عبد الحليهم عباس (1991) نحسو رؤية لتقدير الخدمات

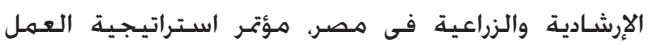

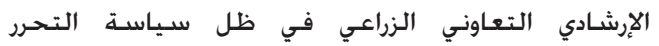

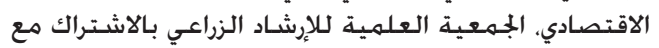

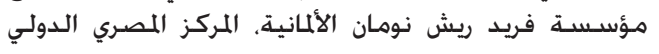
لللزراعة،.

محافظة البحيرة ، مديريـة الزراعة، ســلات قسم الإحسـاء، بيانات غير منشـورة.

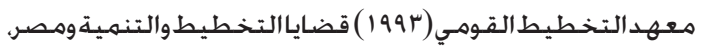
الآثار البيئية للتنميـة الزراعيـة، رقهمّه، القـاهرة.

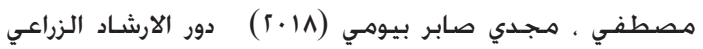

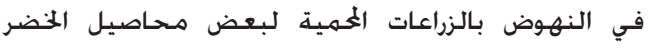
بمهافظة الاسـماعلية ، رسـالة دكتوراه ، ركلية الزية الزراعة بالإسـماعيلية ,جامعة قناة السـويس.

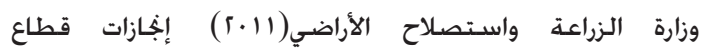

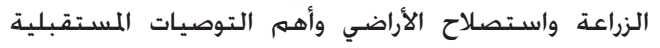

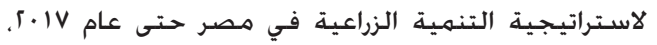
مـركز البـــوث الزراعيـة، الجيزة.

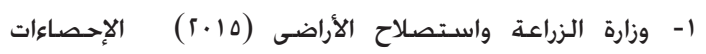

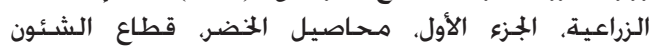
الإقتصادية.

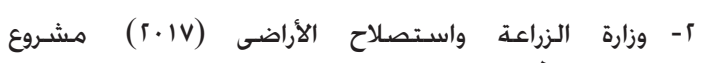
الزراعية المحمية، مركز البحـوث الزراعية، الجيزة.

Krejcie RV and RW Morgan (1970) Educational and Psychological Measurements. College Station, Durham North Carolina, USA, Vol. 30
الرافعي، أحسمد كامل (1995) الإرشاد الزراعي عله وتطبيق،

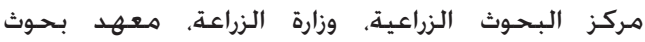
الإرشـاد الزراعي والتنـمية الريفية.

حـفي، قدري (دكتور) علم النفس الصناعي، مطبعة عين شـمس،

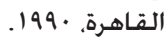

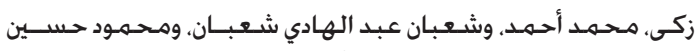

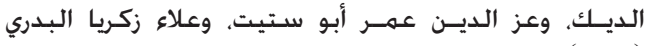

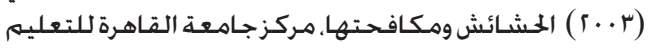
المفتوح، جامعة القاهرة.

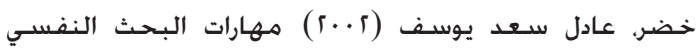

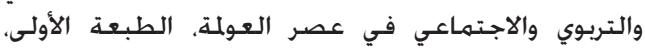
مكتبـة النهضـة المصريـة، القاهـرة.

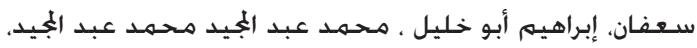

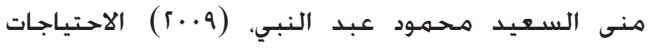

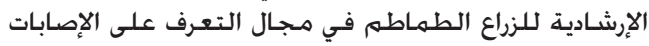

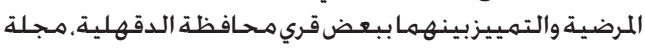

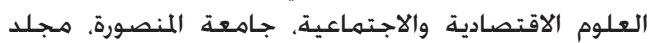

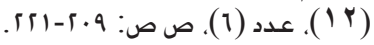

سـلام، على عبد العظيه (1991) المنهـج ومفهومهد وأسـس بناءه

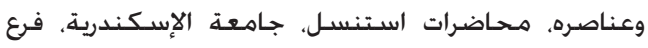
دمنهور.

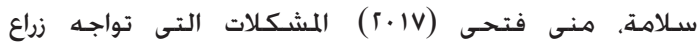

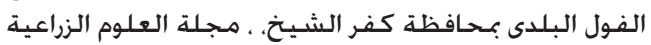

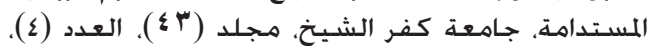
n

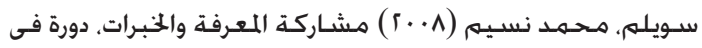

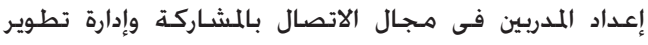

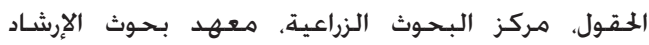

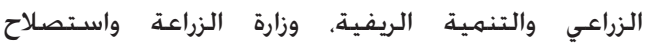
الأراضي، القـاهـرة.

عبد الله، أحمـد مصطفى، ابتسـام بسـيونى راضى، وسـالى محهمد

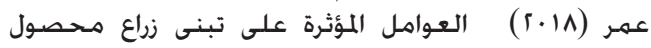

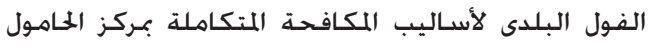

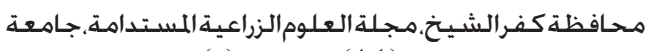

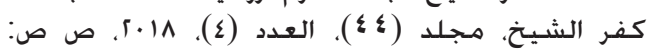

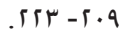




\title{
Greenhouses Farmer's Knowledge of Technical Recommendation of Integrated Pest Control for Vegetable Crops in El Behira Governorate
}

\author{
Mohamed H Algazzar ${ }^{1}$, Ibtisam B. Elmeligy ${ }^{2}$ and Mahmoud Saad lkhawas ${ }^{2}$ \\ ${ }^{1}$ Branch of Agricultural Extension-Department of Agricultural Economics -Faculty \\ of Agriculture - Kafrelsheikh University \\ ${ }^{2}$ Department of extension programs Research-Institute of Agricultural Extension- \\ Research - Agricultural Research Center
}

$\mathbf{T}$

HE MAIN objective of this research was to determine the degree of knowledge of the researched farmers on the technical recommendations for integrated pest control of vegetable crops in El Behera governorate, represent This study included all the 496 greenhouse farmers in the selected villages, who possessed the greenhouses, based on the inventory lists of the holders of the greenhouses in the Agricultural Cooperative Society in each of the selected villages. The sample size was determined using the equation (Krejies and Morgan). The sample size reached 217 and summarized The most important results of this research are as follows: 1It was found that about $79 \%$ of the respondents came in the medium or low category in relation to the total cognitive level in the technical recommendations for integrated pest control of vegetable crops, and only $21 \%$ of them had a high cognitive level with these recommendations. 2 - It became clear that approximately $64 \%, 65 \%, 95 \%$ and $76 \%$, respectively, of the respondents came with a category of low or medium knowledge level with the technical recommendations of agricultural control, mechanical control, biological control, and chemical control respectively. 3- The results also indicate that the combined independent variables explain $30.5 \%$ of the variance in the dependent variable. 